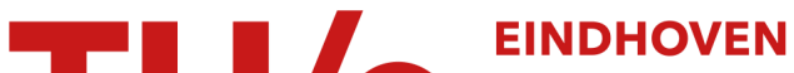 UNIVERSITY OF TECHNOLOGY
}

\section{Modification of kinetic theory for frictional spheres part II}

Citation for published version (APA):

Yang, L., Padding, J. T., \& Kuipers, J. A. M. (2016). Modification of kinetic theory for frictional spheres part II: Model validation. Chemical Engineering Science, 152, 783-794. https://doi.org/10.1016/j.ces.2016.06.015

DOI:

10.1016/j.ces.2016.06.015

Document status and date:

Published: 02/10/2016

\section{Document Version:}

Accepted manuscript including changes made at the peer-review stage

\section{Please check the document version of this publication:}

- A submitted manuscript is the version of the article upon submission and before peer-review. There can be important differences between the submitted version and the official published version of record. People interested in the research are advised to contact the author for the final version of the publication, or visit the $\mathrm{DOI}$ to the publisher's website.

- The final author version and the galley proof are versions of the publication after peer review.

- The final published version features the final layout of the paper including the volume, issue and page numbers.

Link to publication

\section{General rights}

Copyright and moral rights for the publications made accessible in the public portal are retained by the authors and/or other copyright owners and it is a condition of accessing publications that users recognise and abide by the legal requirements associated with these rights.

- Users may download and print one copy of any publication from the public portal for the purpose of private study or research.

- You may not further distribute the material or use it for any profit-making activity or commercial gain

- You may freely distribute the URL identifying the publication in the public portal.

If the publication is distributed under the terms of Article 25fa of the Dutch Copyright Act, indicated by the "Taverne" license above, please follow below link for the End User Agreement:

www.tue.nl/taverne

Take down policy

If you believe that this document breaches copyright please contact us at:

openaccess@tue.nl

providing details and we will investigate your claim. 


\title{
Modification of Kinetic Theory of Granular Flow for Frictional Spheres, Part II: Model validation
}

\section{L. (Lei) Yang, J.T. (Johan) Padding*, J.A.M. (Hans) Kuipers}

Department of Chemical Engineering and Chemistry, Eindhoven University of Technology, 5600 MB, Eindhoven, The Netherlands

Corresponding author's: J.T.Padding@tue.nl

Keywords: Fluidized granular bed; Rough particles; Multiphase flow; Two-fluid model; Discrete particle model; PIV-DIA

\begin{abstract}
The hydrodynamics of a dense solid-gas fluidized bed is studied, using a two fluid model (TFM) based on our newly developed kinetic theory of granular flow (KTGF) for rotating rough particles. The TFM simulations are validated by comparing with PIV-DIA experimental data (Buist et al., 2014) and results obtained from discrete particle model (DPM) simulations of the bubbling fluidized bed. The TFM model predictions agree well with the experimental results for the time-averaged particle axial velocity and solids volume fraction. The predicted levels of the translational granular temperatures and solids circulation patterns compare reasonably well with the results obtained from the DPM simulations. The predicted rotational granular temperature in our TFM simulations shows an almost uniform distribution in the bed as a result of the assumptions that both the local mean rotational velocity and the gradient of the rotational granular temperature at the wall are zero, indicating directions for future improvement. A comparison between TFM simulations using the present KTGF model, and a more simple kinetic theory for rapid flow of slightly frictional, nearly elastic spheres derived by Jenkins and Zhang (2002), is carried out to investigate the influence of particle friction in the fluidized bed. The present KTGF model leads to better agreement with DPM simulations and experimental results for the axial particle velocity profiles and solids volume fraction distribution.
\end{abstract}

\section{Introduction}

Gas-solid fluidized beds are widely employed in processes involving reactions, combustion, separation and classification in the petrochemical, pharmaceutical and energy industries. The design and scale-up of these industrial devices require a better understanding of the dynamics of dense gas-solid flows. Owing to the enormous increase in computer power and algorithmic developments, fundamental modelling of multiphase reactors has become an effective tool to provide both qualitative and quantitative insight into complex gas-solid flows ( $\mathrm{Li}$ et al. 2005; van der Hoef et al., 2006). To describe the hydrodynamics of gassolid flows, Eulerian-Lagrangian models (Tsuji et al., 1993; Hoomans et al., 1996; Walton, 2004) and Eulerian-Eulerian models (Gidaspow, 1994; Enwald et al., 1996; Kuipers and van Swaaij, 1998) have been developed.

Our discrete particle model (DPM) is based on the Eulerian-Lagrangian 'hard sphere' approach. In DPM the solid particles are treated explicitly and their motion is described by Newton's second law. The forces on the particles arise from gravity, the interaction with the fluid phase, and collisions with other particles. For efficiency the averaged continuous fluid phase equations are solved on a grid which is much larger than the particle size. As a result, both a drag-force closure and a collision model have to be specified for DPM. Details of the DPM model and its application are given by Ristow (2000), Deen et al. (2007), and Zhu et al. (2007). The DPM can account for the particle-particle interactions in a fundamental and detailed manner. To understand the capablity of the continuum TFM model, the DPM can be used as 
a 'numerical laboratory' to validate the underlying assumptions in closures adopted for the solid phase in the KTGF theory.

The two-fluid model (TFM) is based on the Eulerian-Eulerian approach. In TFM the solid phase is treated as a second continuum, interpenetrating with the continuous gas phase. Balance equations for mass, momentum and energy are solved by using additional closure equations for stress, viscosities, thermal conductivities, and energy dissipation rates (Kuipers et al., 1992; Wang et al., 2012). The EulerEuler approach has emerged as a very promising tool as a result of its compromise between computational cost and amount of detail provided. The challenge of the model is to establish an accurate hydrodynamic and rheological description of the solid phase. State-of-the-art closures have been obtained from the kinetic theory of granular flow (Jenkins \& Savage, 1983; Ding \& Gidaspow, 1990; Nieuwland et al., 1995). The earliest and most widely used KTGF models have been derived for dilute flows of inelastic, smooth, frictionless spheres. However, real particles are usually rough and frictional, leading to particle rotation. More sophisticated models have been developed (Lun, 1991; Goldshtein and Shapiro, 1995; Jenkins and Zhang, 2002; Kumaran, 2006; Chialvo and Sundaresan, 2013; Zhao et al., 2013) that consider particle roughness by including tangential restitution, coefficient of friction and rotational degrees of freedom. However, until now there is no consensus on the best general form for the kinetic theory for rough spheres accounting for the coefficient of friction, the coefficient of tangential restitution and particle rotation.

In Part I, we have derived balance equations for three-dimensional rough spheres, including closure equations for the transport coefficients. A key finding was that the particle stress has an antisymmetric part which may be interpreted as a rotational viscosity.

In this work, we implemented the new closure equations in a three-dimensional extension of the original two-dimensional model (in-house code) developed by Kuipers et al. (1992) and (1993). We will show that the resulting TFM simulation results are in good agreement with PIV-DIA experimental data from Buist et al. (2014) and simulation results obtained with our in-house DPM simulations. The simulated solids circulation patterns, averaged particle axial velocity and granular temperature profiles are compared. Furthermore, a careful comparison is made between the present model (Model A) and the effective model by Jenkins and Zhang (2002) (Model B) for the influence of particle friction.

\section{Summary of kinetic theory of rough spheres}

The balance equations of the new KTGF model, including full expressions for the constitutive equations, are given in Table 1. In this work, the particles have rotational degrees of freedom. During particle collisions not only linear momentum is transferred but also angular momentum. Details of the model can be found in Part I. A more simple kinetic theory for rapid flow of identical, slightly frictional, nearly elastic spheres was derived by Jenkins and Zhang (2002). They introduced an effective coefficient of restitution $e_{\text {eff }}$ to account for the effect of particle friction on the energy dissipation in case the coefficient of friction is small. The calculation of $e_{\text {eff }}$ can be found in Table 2 .

\section{Table 1}

Balance equations and constitutive equations for the frictional KTFG model.

Balance equations:

$$
\begin{aligned}
& \frac{\partial\left(\varepsilon_{g} \rho_{g}\right)}{\partial t}+\nabla \cdot\left(\varepsilon_{g} \rho_{g} \mathbf{v}_{g}\right)=0 \\
& \frac{\partial\left(\varepsilon_{g} \rho_{g}\right)}{\partial t}+\nabla \cdot\left(\varepsilon_{g} \rho_{g} \mathbf{v}_{g}\right)=0
\end{aligned}
$$




$$
\begin{aligned}
& \frac{\partial\left(\varepsilon_{g} \rho_{g} \mathbf{v}_{g}\right)}{\partial t}+\nabla \cdot\left(\varepsilon_{g} \rho_{g} \mathbf{v}_{g} \mathbf{v}_{g}\right)=-\varepsilon_{g} \nabla P_{g}-\nabla \cdot\left(\varepsilon_{g} \boldsymbol{\tau}_{g}\right)+\varepsilon_{g} \rho_{g} \mathbf{g}-\beta_{A}\left(\mathbf{v}_{g}-\mathbf{v}_{s}\right) \\
& \frac{\partial\left(\varepsilon_{s} \rho_{s} \mathbf{v}_{s}\right)}{\partial t}+\nabla \cdot\left(\varepsilon_{s} \rho_{s} \mathbf{v}_{s} \mathbf{v}_{s}\right)=-\varepsilon_{s} \nabla P_{g}-\nabla \cdot\left(P_{s} \mathbf{I}+\varepsilon_{s} \boldsymbol{\tau}_{s}\right)+\varepsilon_{s} \rho_{s} \mathbf{g}+\beta_{A}\left(\mathbf{v}_{g}-\mathbf{v}_{s}\right) \\
& \frac{3}{2}\left[\frac{\partial\left(\varepsilon_{s} \rho_{s} \Theta_{t}\right)}{\partial t}+\nabla \cdot\left(\varepsilon_{s} \rho_{s} \mathbf{v}_{s} \Theta_{t}\right)\right]=-\nabla \mathbf{v}_{s}:\left(P_{s} \mathbf{I}+\varepsilon_{s} \boldsymbol{\tau}_{s}\right)+\varepsilon_{s} \nabla \cdot\left(\kappa_{t} \nabla \Theta_{t}\right)-\gamma_{t}-3 \beta_{A} \Theta_{t} \\
& \frac{3}{2}\left[\frac{\partial\left(\varepsilon_{s} \rho_{s} \Theta_{r}\right)}{\partial t}+\nabla \cdot\left(\varepsilon_{s} \rho_{s} \mathbf{v}_{s} \Theta_{r}\right)\right]=\varepsilon_{s} \nabla \cdot\left(\kappa_{r} \nabla \Theta_{r}\right)-\gamma_{r}
\end{aligned}
$$

Solids pressure tensor:

$$
\mathrm{P}_{s}=\varepsilon_{s} \rho_{s} \Theta_{t}\left[1+2(1+e) \varepsilon_{s} g_{0}\right]
$$

Bulk viscosity:

$$
\lambda_{s}=\frac{4}{3} \varepsilon_{s} \rho_{s} \sigma g_{0}(1+e) \sqrt{\frac{\Theta_{t}}{\pi}}
$$

Solids stress tensor:

$$
\boldsymbol{\tau}_{s}=-\left\{\left(\lambda_{s}-\frac{2}{3} \mu_{t_{s}}\right)\left(\nabla \cdot \mathbf{v}_{s}\right) \mathbf{I}+\mu_{t_{s}}\left[\nabla \mathbf{v}_{s}+\left(\nabla \mathbf{v}_{s}\right)^{T}\right]+\mu_{r_{s}}\left[\nabla \mathbf{v}_{s}-\left(\nabla \mathbf{v}_{s}\right)^{T}\right]\right\}
$$

Gas stress tensor:

$$
\boldsymbol{\tau}_{g}=-\left\{\left(\lambda_{g}-\frac{2}{3} \mu_{g}\right)\left(\nabla \cdot \mathbf{v}_{g}\right) \mathbf{I}+\mu_{g}\left[\nabla \mathbf{v}_{g}+\left(\nabla \mathbf{v}_{g}\right)^{T}\right]\right\}
$$

Translational energy dissipation rate:

$$
\gamma_{t}=\Theta_{t} g_{0} \rho_{s} \varepsilon_{s}^{2}\left\{\begin{array}{l}
-\frac{192}{\sigma} \sqrt{\frac{\Theta_{t}}{\pi}}\left[\eta_{1}\left(1+\eta_{1}\right)-(2 \lambda+1) \mathrm{A}_{1}+(\lambda+1) \mathrm{A}_{2}\right] \\
+12 \nabla \cdot \mathbf{v}_{s}\left[\eta_{1}\left(1+\eta_{1}\right)+5\left[(\lambda+1) \mathrm{A}_{4}-(2 \lambda+1) \mathrm{A}_{3}\right.\right.
\end{array}\right\}
$$

Rotational energy dissipation rate:

$$
\gamma_{r}=\Theta_{t} g_{0} \rho_{s} \varepsilon_{s}^{2}\left\{-\frac{96}{\sigma} \sqrt{\frac{\Theta_{t}}{\pi}}\left(\frac{5}{2} \mathrm{~A}_{2}-\lambda \mathrm{A}_{1}\right)+120 \nabla \cdot \mathbf{v}_{s}\left(\frac{5}{2} \mathrm{~A}_{4}-\lambda \mathrm{A}_{3}\right)\right\}
$$

Translational shear viscosity:

$$
\mu_{t_{s}}=\bar{\mu}\left(1+\mu_{t_{s, c}}\right)+\frac{3}{5} \lambda_{s}, \quad \mu_{t_{s, c}}=-0.8 \varepsilon_{s} g_{0}\left[-6(2 \lambda+1) \mathrm{A}_{1}+2 \eta_{1}\right]
$$

Rotational shear viscosity:

$$
\mu_{r_{s}}=-8(2 \lambda+1) \sigma g_{0} \rho_{s} \varepsilon_{s}^{2} A_{1} \sqrt{\frac{\Theta_{t}}{\pi}}
$$

Pseudo translational thermal conductivity:

$$
\kappa_{t}=\bar{\kappa}_{t}\left(1+\kappa_{t_{s, c}}\right)+\frac{3}{2} \lambda_{s}, \kappa_{t_{s, c}}=-\varepsilon_{s} g_{0}\left(2 \eta_{1}-16(2 \lambda+1) \mathrm{A}_{1}\right)
$$

Pseudo rotational thermal conductivity: 


$$
\begin{aligned}
& \kappa_{r}=\bar{\kappa}_{r}+\kappa_{r_{s, c}}, \kappa_{r_{s, c}}=16 \lambda(\lambda+1) g_{0} \varepsilon_{s} \sigma \frac{\Theta_{t}}{\Theta_{r}} \sqrt{\frac{\Theta_{t}}{\pi}} \mathrm{A}_{1} \\
& \bar{\kappa}_{r} \equiv \frac{L_{3}}{2 L_{1}} \rho \\
& L_{1}=\frac{-32 \sigma \varepsilon_{s} g_{0}}{25} \sqrt{\frac{\Theta_{t}}{\pi}}\left[\frac{50 \mathrm{~A}_{2}}{\lambda}-10 \mathrm{~A}_{1}-\frac{100}{3} \mathrm{~A}_{11}-\frac{50}{3 \lambda}(\lambda+1)(\lambda+2) \mathrm{A}_{12}+\frac{20}{3}(3 \lambda+4) \mathrm{A}_{9}\right] \\
& L_{3}=\left(1+\frac{12}{5} g_{0} \varepsilon_{s}\right) \lambda \Theta_{t}\left[-\frac{8 \eta_{1}(2+\lambda)}{3(1+\lambda)}+50\left(1+\eta_{1}\right) \mathrm{A}_{3}\right]
\end{aligned}
$$

Radial distribution function at contact (Ma and Ahmadi, 1986):

$$
g_{0}=1+4 \varepsilon_{s} \frac{1+2.5 \varepsilon_{s}+4.5904 \varepsilon_{s}^{2}+4.515439 \varepsilon_{s}^{3}}{\left[1-\left(\varepsilon_{s} / \varepsilon_{s}^{\max }\right)^{3}\right]^{0.67802}}
$$

Where, $A_{1}, A_{2}, A_{3}, A_{4}, A_{6}, A_{7}, A_{9}, A_{11}, A_{12}, A_{13}$ are integrals of trigonometric functions and can be found in Appendix B of Part I, and $\lambda=\frac{5 \Theta_{r}}{2 \Theta_{t}}$ is the ratio of rotational to translational granular temperature.

Table 2

Effective coefficient of restitution (Jenkins and Zhang, 2002).

$$
\begin{aligned}
& e_{\text {eff }}=e-\frac{1}{2} a_{1}+\frac{1}{2} a_{2} \frac{b_{1}}{b_{2}} \\
& a_{1}=\frac{\mu}{\mu_{0}}\left[\pi \mu_{0}\left(1-\frac{2}{\pi} \arctan \mu_{0}\right)+\frac{2 \mu_{0}^{2}}{1+\mu_{0}^{2}}\left(1-2 \frac{\mu}{\mu_{0}}\right)\right] \\
& a_{2}=\frac{5 \mu}{2 \mu_{0}}\left[\frac{\pi}{2} \mu_{0}\left(1-\frac{2}{\pi} \arctan \mu_{0}\right)+\frac{\mu_{0}^{2}-\mu_{0}^{4}}{\left(1+\mu_{0}^{2}\right)^{2}}\right] \\
& b_{1}=\left(\frac{\mu}{\mu_{0}}\right)^{2} \frac{\mu_{0}^{2}}{1+\mu_{0}^{2}} \\
& b_{2}=\frac{\mu}{2 \mu_{0}}\left[\frac{\pi}{2} \mu_{0}\left(1-\frac{2}{\pi} \arctan \mu_{0}\right)+\frac{\mu_{0}^{2}}{1+\mu_{0}^{2}}\right] \\
& \frac{\Theta_{r}}{\Theta_{t}}=\frac{b_{1}}{b_{2}}, \mu_{0}=\frac{7}{2} \frac{\mu(1+e)}{1+\beta_{0}}
\end{aligned}
$$




\section{Numerical simulations}

\subsection{Initial conditions, boundary conditions, and parameter settings}

The Euler-Euler simulations based on the new KTGF model and the Euler-Lagrange simulations are carried out for a bubbling rectangular pseudo-2D fluidized bed, with particle and domain properties listed in Table 3. No-slip boundary conditions for the side walls (left, right, front and back side of the rectangular domain) are used for the gas phase. At the bottom inlet, a uniform gas velocity is specified, whereas at the top outlet, atmospheric pressure $(101,325 \mathrm{~Pa})$ is prescribed. For the solid phase, partial slip boundary conditions are used on all walls. A relation for the solids velocity gradient and an expression for the pseudo Fourier fluctuation energy flux at the wall have been given by Sinclair and Jackson (1989), which has been used by Lu et al. (2004) and Verma et al. (2013)

$$
\begin{gathered}
-\varepsilon_{s} \mu_{s} \frac{\partial v_{z}}{\partial r}=\frac{\pi \rho_{s} v_{z} \alpha \sqrt{\Theta_{t}}}{2 \sqrt{3}\left[\frac{\varepsilon_{s, \text { max }}}{\varepsilon_{s}}-\left(\frac{\varepsilon_{s, \max }}{\varepsilon_{s}}\right)^{2 / 3}\right]} \\
-\kappa_{t} \frac{\partial \Theta_{t}}{\partial r}=\frac{-2 v_{z}^{2} \alpha+3\left(1-e_{w}^{2}\right) \Theta_{t}}{12\left[\frac{\varepsilon_{s, \max }}{\varepsilon_{s}}-\left(\frac{\varepsilon_{s, \max }}{\varepsilon_{s}}\right)^{2 / 3}\right]} \pi \rho_{s} \sqrt{3 \Theta_{t}}
\end{gathered}
$$

For the rotational granular temperature at the wall, we currently assume adiabatic conditions, i.e. $-\kappa_{r} \frac{\partial \Theta_{r}}{\partial r}=0$. This rather crude assumption is made because a theoretical treatment of the rotational granular heat flux for our model is more involved and the topic of our current research. As initial conditions, the solid volume fraction is set to 0.597 throughout the bed, solid velocities are set to zero, and the gas velocity is set in accordance with the inflow boundary conditions.

\section{Table 3}

Properties of particle and settings for model validation.

\begin{tabular}{lll}
\hline Parameters & DPM & TFM \\
\hline Particle & glass $\left(\rho=2526 \mathrm{~kg} / \mathrm{m}^{3}\right)$ & glass $\left(\rho=2526 \mathrm{~kg} / \mathrm{m}^{3}\right)$ \\
Particle diameter, $\sigma$ & $3 \mathrm{~mm}$ & $3 \mathrm{~mm}$ \\
Initial bed height & - & $0.30 \mathrm{~m}$ \\
Domain size & $0.3 \times 0.015 \times 0.9 \mathrm{~m}$ & $0.3 \times 0.015 \times 0.9 \mathrm{~m}$ \\
Particle number & 57000 & - \\
Grid number $(\mathrm{x} \times \mathrm{y} \times \mathrm{z})$ & $30 \times 2 \times 90$ & $30 \times 3 \times 90$ \\
Normal spring stiffness & $k_{\mathrm{n}}=12000 \mathrm{~N} / \mathrm{m}$ & \\
Coefficient of normal restitution, $e$ & 0.97 & 0.97 \\
Coefficient of tangential restitution, $\beta_{0}$ & 0.33 & 0.33 \\
Coefficient of friction, $\mu$ & 0.1 & 0.1 \\
Particle-wall collisions & &
\end{tabular}


Coefficient of normal restitution, $e_{\mathrm{w}}$ Coefficient of tangential restitution, $\beta_{\mathrm{w}}$ Coefficient of friction, $\mu_{\mathrm{w}}$ Specularity coefficient, $\alpha$ Initial bed voidage

Simulation time Superficial gas velocity, $U_{\mathrm{g}}$ Drag relation

Flow solver time step
0.97

0.33

0.1

$-$

0.403

$25 \mathrm{~s}$

$2.35 \mathrm{~m} / \mathrm{s}, 3.28 \mathrm{~m} / \mathrm{s}$

Ergun (1952), and Wen \&

Yu (1966)

$10^{-5} \mathrm{~s}$
0.97

0.1

0.403

$25 \mathrm{~s}$

$2.35 \mathrm{~m} / \mathrm{s}, 3.28 \mathrm{~m} / \mathrm{s}$

Ergun (1952), and Wen \&

Yu (1966)

$10^{-5} \mathrm{~s}$

\subsection{Momentum exchange coefficient}

A proper drag model for the description of the momentum exchange coefficient is vital for an adequate description of fluidized beds. Many studies (e.g. Wen and Yu, 1966; Van der Hoef et al., 2005; Ozel et al., 2009) have been dedicated to obtaining accurate drag relations. The drag model that is used most frequently in numerical models is a combination of the Ergun equation (1952), originally developed for packed beds, at low porosities,

$$
\beta_{A}=150 \frac{\varepsilon_{s}^{2}}{\varepsilon_{g}} \frac{\mu_{g}}{\sigma^{2}}+1.75 \frac{\varepsilon_{s} \rho_{g}}{\sigma}\left|\mathbf{v}_{g}-\mathbf{v}_{s}\right|, \quad\left(\text { for } \varepsilon_{g} \leq 0.8\right)
$$

and the Wen \& Yu equation at high porosities:

$$
\beta_{A}=\frac{3}{4} C_{d} \frac{\varepsilon_{s} \rho_{g}}{\sigma}\left|\mathbf{v}_{g}-\mathbf{v}_{s}\right| \varepsilon_{g}^{-1.65}, \quad\left(\text { for } \varepsilon_{g}>0.8\right. \text { ) }
$$

Here the single sphere drag coefficient is given by:

$$
C_{d}= \begin{cases}\frac{24}{\operatorname{Re}}\left(1+0.15 \mathrm{Re}^{0.687}\right), & (\text { for } \operatorname{Re} \leq 1000) \\ 0.44, & (\text { for } \operatorname{Re}>1000)\end{cases}
$$

which depends on the particle Reynolds number $\mathrm{Re}=\varepsilon_{g} \rho_{g} \sigma\left|\mathbf{v}_{g}-\mathbf{v}_{s}\right| / \mu_{g}$.

\subsection{Measurements of particle height, granular temperature, and energy budget}

The time evolution of the averaged particle height $\langle h\rangle(t)$ can be used to characterize the bed expansion dynamics. We will compare $\langle h\rangle(t)$ predicted by our TFM simulations with the one predicted by (more detailed) DPM simulations. In the latter case, the averaged particle height follows from a numerical average:

$$
\langle h\rangle=\frac{1}{N_{\text {part }}} \sum_{i}^{N_{\text {part }}} h_{i}
$$

where $h_{i}$ is the height of particle $i$ and $N_{\text {part }}$ is the total number of particles in the simulation domain. In TFM simulations, to obtain an equivalent estimate of the averaged particle height, we should take a weighted average, i.e. we should weight by the solids volume fraction $\varepsilon_{s, k}$ of each cell $k$ : 


$$
\langle h\rangle=\frac{\sum_{k}^{N_{c e l l}} \varepsilon_{s, k} h_{k}}{\sum_{k}^{N_{c e l l}} \varepsilon_{s, k}}
$$

Where $h_{k}$ is the height of cell $k$, and $N_{\text {cell }}$ is the number of cells in the simulation domain.

The granular temperature characterizes the amount of random motion of individual particles in a small region during a small period. It is not only an important characteristic for the dynamics of gas-solid fluidization (Van der Hoef, 2006), but also an essential variable in TFM simulations because it determines the solids pressure and transport properties. It is therefore important to compare the granular temperature predicted by our TFM model with the granular temperature measured in DPM simulations. To this end, in each computational cell $k$ of the DPM simulations, we first determine the averaged translational and rotational solid velocities of all $N_{\text {part }, k}$ particles located in that cell:

$$
\left\langle\mathbf{v}_{s}\right\rangle_{k}=\frac{1}{N_{p a r t, k}} \sum_{i}^{N_{\text {part }, k}} \mathbf{v}_{i}, \quad\left\langle\boldsymbol{\omega}_{s}\right\rangle_{k}=\frac{1}{N_{p a r t, k}} \sum_{i}^{N_{\text {par }, k}} \boldsymbol{\omega}_{i}
$$

The translational granular temperature in cell $k$ is then computed as:

$$
\Theta_{t, k}=\frac{1}{3 N_{p a r t, k}} \sum_{i}^{N_{\text {part }, k}}\left(\mathbf{v}_{i}-\left\langle\mathbf{v}_{s}\right\rangle_{k}\right)^{2}
$$

while the rotational granular temperature in cell $k$ is computed as:

$$
\Theta_{r, k}=\frac{I}{3 m N_{p a r t, k}} \sum_{i}^{N_{\text {part }, k}}\left(\boldsymbol{\omega}_{i}-\left\langle\boldsymbol{\omega}_{s}\right\rangle_{k}\right)^{2}
$$

Finally, we compare the particle energy budgets for the TFM (as described in Goldschmidt et al., 2004) and DPM (as described in Van der Hoef et al., 2006). We distinguish between translational kinetic energy $E_{k i n}$, rotational granular energy $E_{\text {rotgran, }}$ and gravitational potential energy $E_{\text {pot. }}$ The translational kinetic energy is further subdivided into a convective contribution $E_{\text {conv }}$ (based on the cell-averaged velocities) and translational granular energy $E_{\text {gran }}$ (based on the fluctuating velocities). Detailed expressions are given in Table 4.

\section{Table 4}

Expressions for the particle energy budget.

\begin{tabular}{lll}
\hline & Discrete particle model & Two fluid model \\
\hline$E_{\text {kin }}$ & $\sum_{i}^{N_{\text {part }}} \frac{1}{2} m_{i} v_{i}^{2}$ & - \\
$E_{\text {conv }}$ & $\sum_{k}^{N_{\text {cell }}} \frac{1}{2} m N_{\text {part }, k}\left\langle\mathbf{v}_{s}\right\rangle_{k}^{2}$ & $\sum_{k}^{N_{\text {cell }}} \frac{1}{2} \varepsilon_{s, k} \rho_{s} v_{s, k}^{2} V_{\text {cell }, k}$
\end{tabular}




$$
\begin{array}{lll}
E_{\text {gran }} & \sum_{k}^{N_{\text {cell }}} \frac{3}{2} m N_{\text {part }, k} \Theta_{t, k} & \sum_{k}^{N_{\text {cell }}} \frac{3}{2} \varepsilon_{s, k} \rho_{s} \Theta_{t, k} V_{\text {cell }, k} \\
E_{\text {rogrant }} & \sum_{k}^{N_{\text {cell }}} \frac{3}{2} m N_{\text {part }, k} \Theta_{r, k} & \sum_{k}^{N_{\text {cell }}} \frac{3}{2} \varepsilon_{s, k} \rho_{s} \Theta_{r, k} V_{c e l l, k} \\
E_{\text {pot }} & \sum_{i}^{N_{\text {part }}} m g h_{i} & \sum_{k}^{N_{\text {cell }}} \varepsilon_{s, k} \rho_{s} g h_{k} V_{\text {cell }, k}
\end{array}
$$

Here $V_{\text {cell, }, k}$ is the volume of the cell $k$. All the energy terms in both DPM and TFM are calculated every $0.05 \mathrm{~s}$ and averaged over a time span of $10 \mathrm{~s}$.

\section{Results and discussion}

In this part, the present TFM model (model A) is validated by comparing with PIV-DIA experimental data from Buist et al. (2014) and detailed data obtained from DPM simulations, focusing on particleparticle and gas-particle interactions. At the same time, we compare the present model with a TFM model (Model B) which is based on smooth sphere KTGF, but using an effective coefficient of restitution as derived by Jenkins and Zhang (2002) (Table 2).

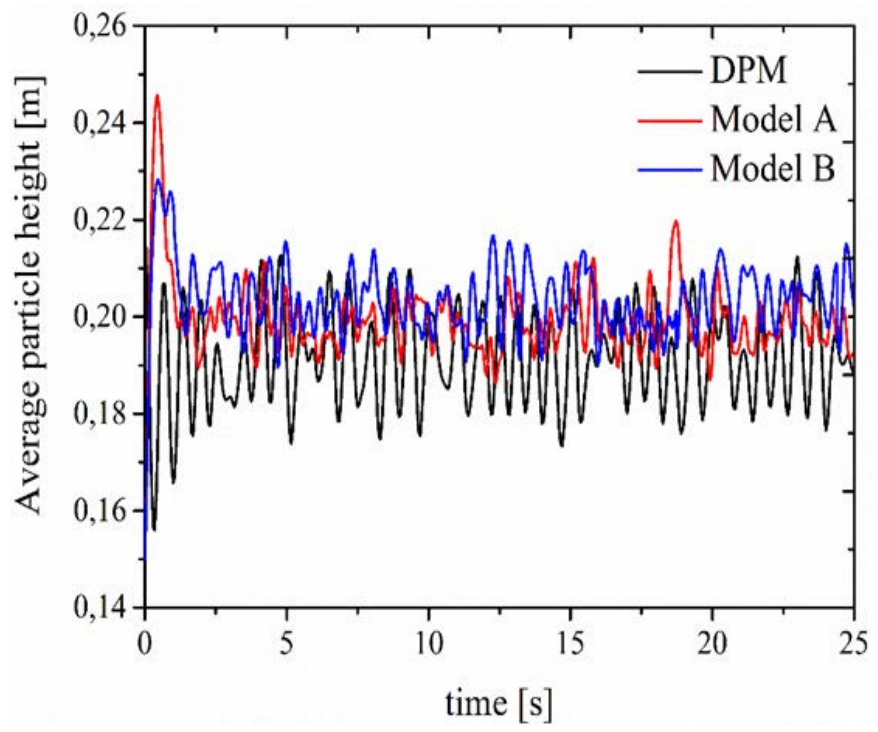

Fig. 1. Comparison of simulated average particle height, $U_{g}=2.35 \mathrm{~m} / \mathrm{s}$.

Fig. 1 shows the average particle height in the bed. The simulated results from model A and model B are very similar to those obtained from DPM, both in term of the average bed height and the fluctuations in bed height. However, the dynamics of the bed expansion predicted from model B is more pronounced than that from model A. The deviation can be attributed to the underestimation of energy losses during particle-particle collisions in model B.

Next we focus on the solids circulation patterns. Due to coalescence, the bubbles increase rapidly in size as they move upwards in the bed. As a consequence, a zone of increased bubble development, initially close to the bottom wall near the gas inlet, is displaced towards the center of the bed with 
increasing height above the gas inlet. Particles appear to flow upwards in regions of more intense bubble activity and downwards in regions of lesser bubble activity, which results in the formation of a pronounced global solids circulation pattern with two symmetric vortices at the top half of the bed. Fig. 2 shows the time-averaged solids circulation patterns from three models and the experiment for two different superficial gas velocities. The simulation results from model A, model B and DPM show close agreement with experimental findings at a superficial gas velocity of $2.35 \mathrm{~m} / \mathrm{s}$. It can be observed quantitatively that the solids in both models A and B move more vigorously through the fluidized bed than predicted by the DPM simulations. When the superficial gas velocity is increased to $3.28 \mathrm{~m} / \mathrm{s}$, the top vortices become elongated and a pronounced global solids circulation appears. This corresponds well to observations by many others (Laverman et al., 2012; Goldschmidt et al., 2004, Dan et al., 2009) that the lateral movement of the bubbles is enhanced at higher fluidization velocities caused by the increased circulation of the emulsion phase. The macroscopic circulation patterns for the DPM and the TFM models are similar.

(a)

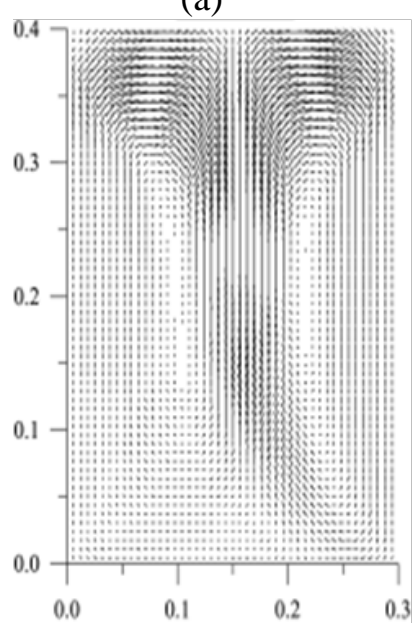

(e) (b)

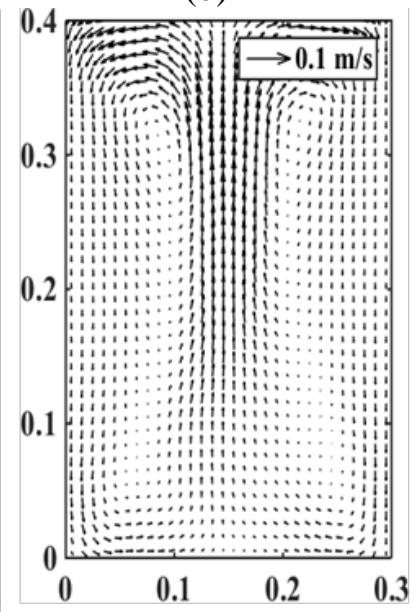

(c)

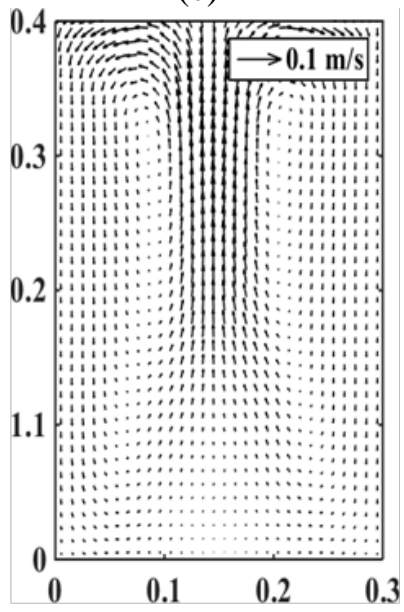

(d)

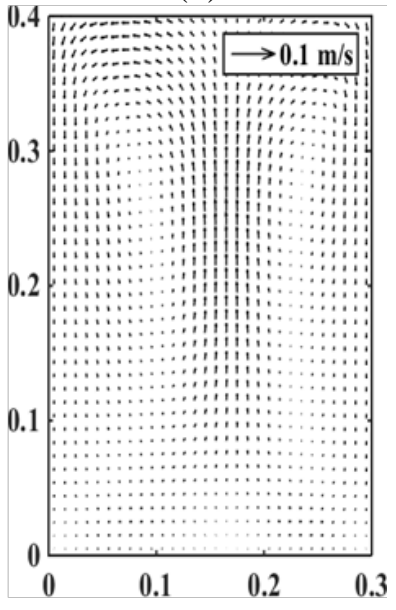

(g)
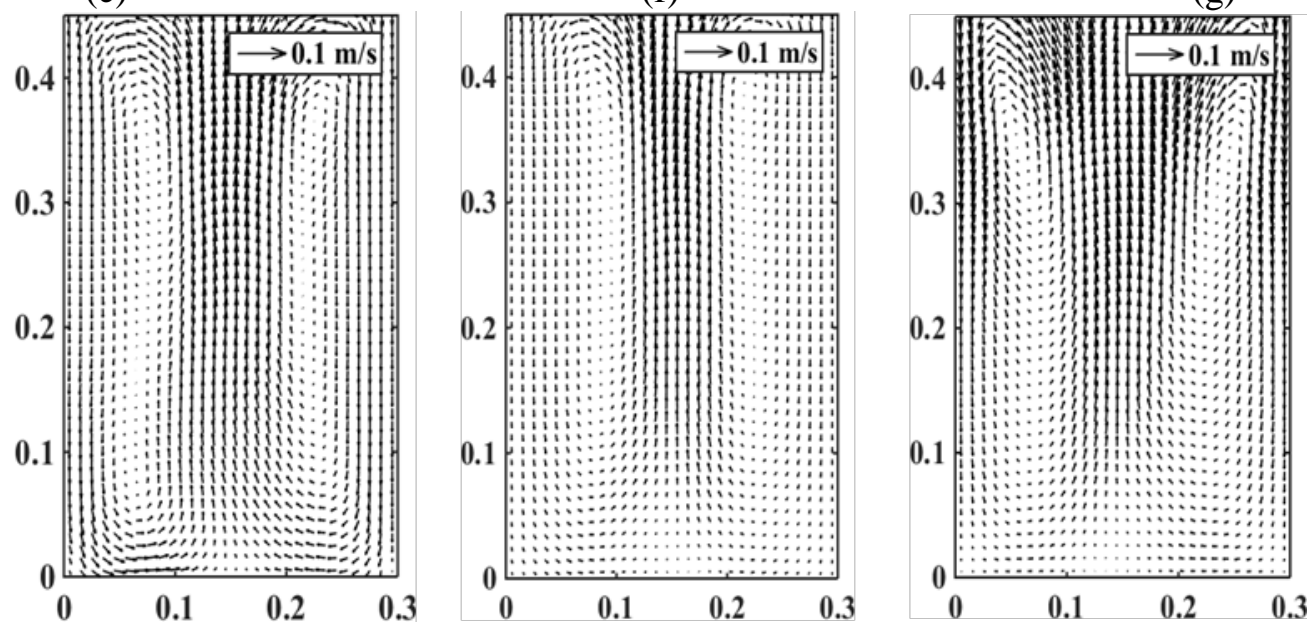

Fig. 2. Time-averaged particle velocity from experiment and simulations. Upper row: $U_{\mathrm{g}}=2.35 \mathrm{~m} / \mathrm{s}$, (a) PIV-DIA (Buist et al., 2014); (b) Model A; (c) Model B; (d) DPM simulation; Lower row: $U_{\mathrm{g}}=3.28 \mathrm{~m} / \mathrm{s}$, (e) Model A; (f) Model B; (g) DPM simulation.

Figs. 3 and 4 show a comparison of time-averaged axial particle velocity components at different superficial gas velocities. The axial particle velocity is positive in the center and negative near the walls, 
which indicates that particles move upward in the center and flow down near the wall. At the lower gas velocity $(2.35 \mathrm{~m} / \mathrm{s})$, the simulated particle axial velocity from both model A and model B overpredict the ascending and descending velocity magnitudes. At higher gas velocity $(3.28 \mathrm{~m} / \mathrm{s})$, the predicted particle velocities in the center agree well with the experiment and the DPM simulation at the height of $0.1 \mathrm{~m}$. At larger heights $(\mathrm{z}=0.2 \mathrm{~m}$ and $\mathrm{z}=0.3 \mathrm{~m})$, the simulated particle velocity from both model A and model B are lower in magnitude than observed in the experiments. There are deviations for the velocities near the wall for all three models, including DPM, especially at lower superficial gas velocity. Van Buijtenen et al. (2011) also found such deviations in spout fluidized beds. Still, both the simulations and the experiment show the same velocity profile trends. Although the predictions for the velocity profiles are similar for models A and B, it can be seen that in most cases model A has a somewhat better agreement with the DPM simulations than model B. The reader should bear in mind that further improvement of model A is foreseen when updated boundary conditions on the particle stress and translational and rotational granular temperature are included.
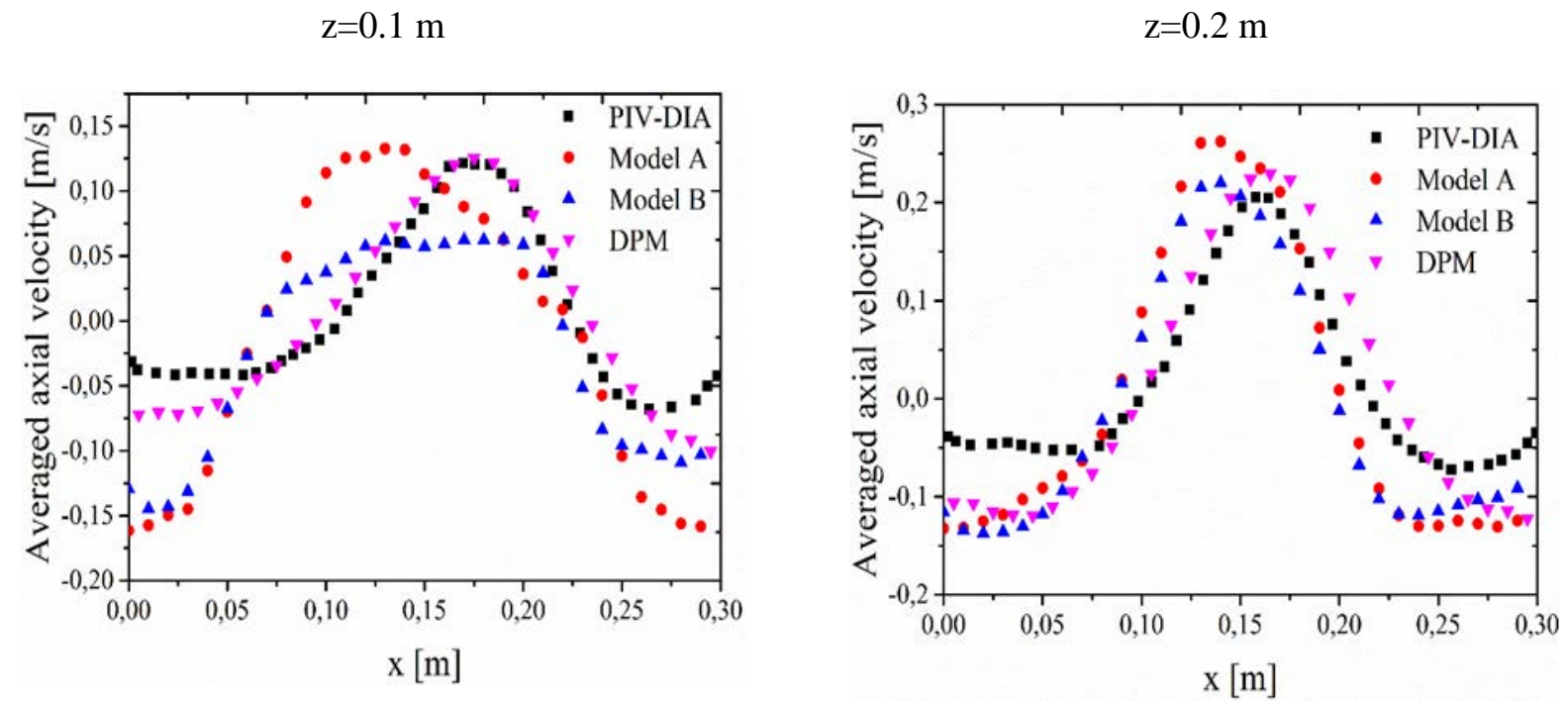

$\mathrm{z}=0.3 \mathrm{~m}$

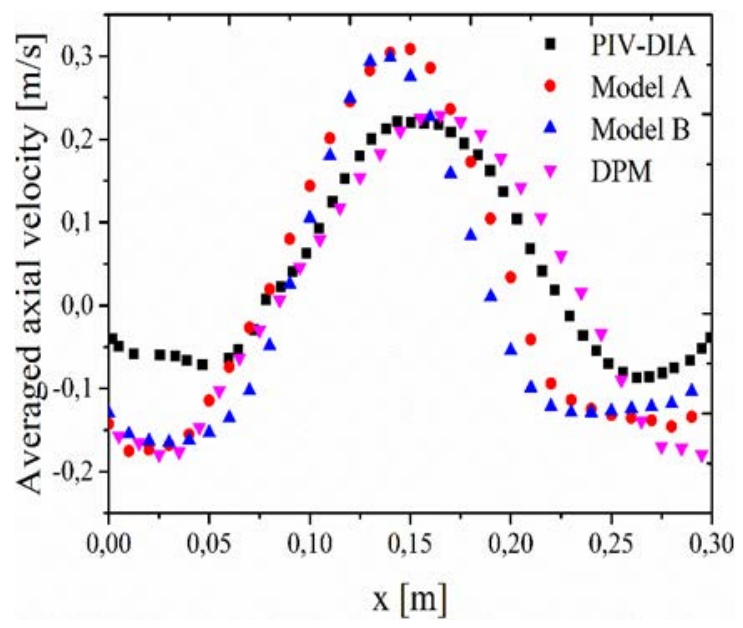

Fig. 3. Comparison of averaged axial particle velocity for PIV-DIA and simulations in vertical direction at three cross-sections of the bed (5-25 s), $U_{g}=2.35 \mathrm{~m} / \mathrm{s}$. 
$\mathrm{z}=0.1 \mathrm{~m}$

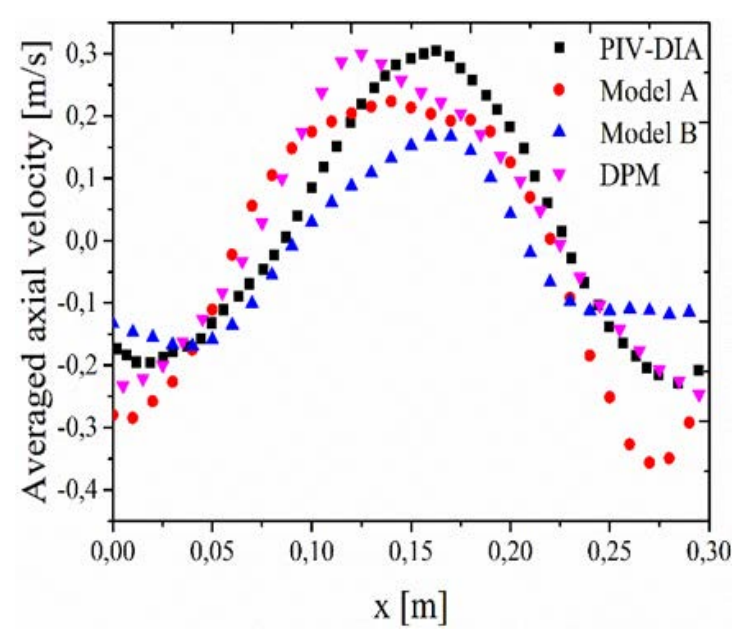

$\mathrm{z}=0.2 \mathrm{~m}$

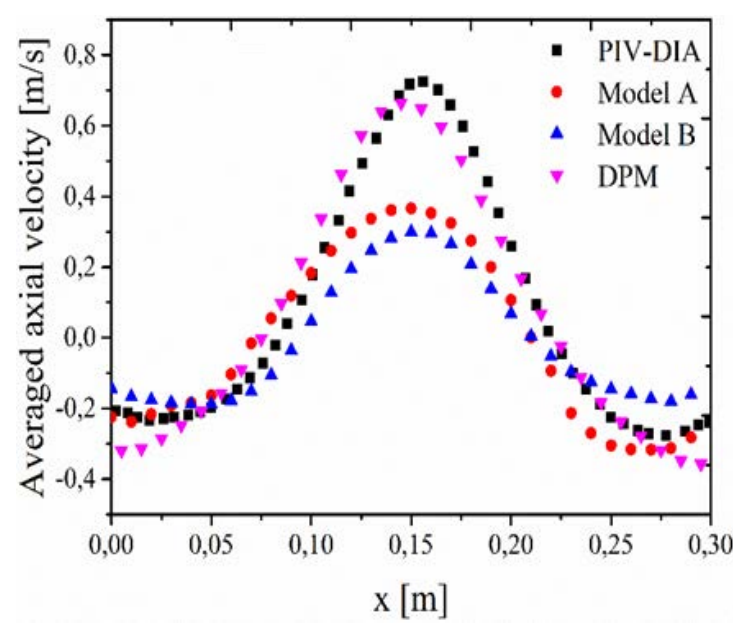

$\mathrm{z}=0.3 \mathrm{~m}$

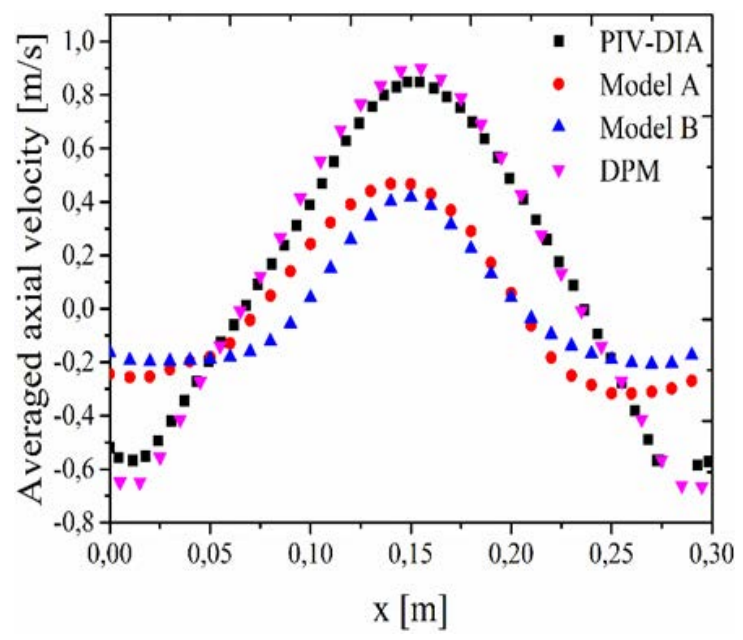

Fig. 4. Comparison of time-averaged particle velocity for PIV-DIA and simulations in vertical direction at three cross-sections of the bed (5-25 s), $U_{g}=3.28 \mathrm{~m} / \mathrm{s}$.

Time-averaged solids fraction distributions from the three models and the PIV-DIA experiment (Buist et al., 2014) based on the algorithm of van Buijtenen et al. (2011) and de Jong et al. (2012) are shown in Fig 5. We note that the PIV-DIA technique lacks accuracy in the measurement of the solids fraction, especially at high solids fractions, so the comparison with experimental results should be done with care. All profiles are qualitatively similar except that the zone of intermediate density (solids fraction 0.360.48 ) moves too much towards the bottom and the side walls for model $B$, while this intermediate density zone remains at the bottom for model A and the more detailed DPM simulations. The dense zones (solids fraction 0.54 or higher) in both model A and model B are a little lifted towards the top of the bed. Overall, the extent of the dense zones predicted by model $\mathrm{A}$ is in good agreement with the extent predicted by DPM simulations and the experiment. On the other hand, the extent predicted by model B is much smaller. In summary, Fig. 5 again shows that model A can provide better agreement with the DPM simulation and the experiment than model B. 
(a)

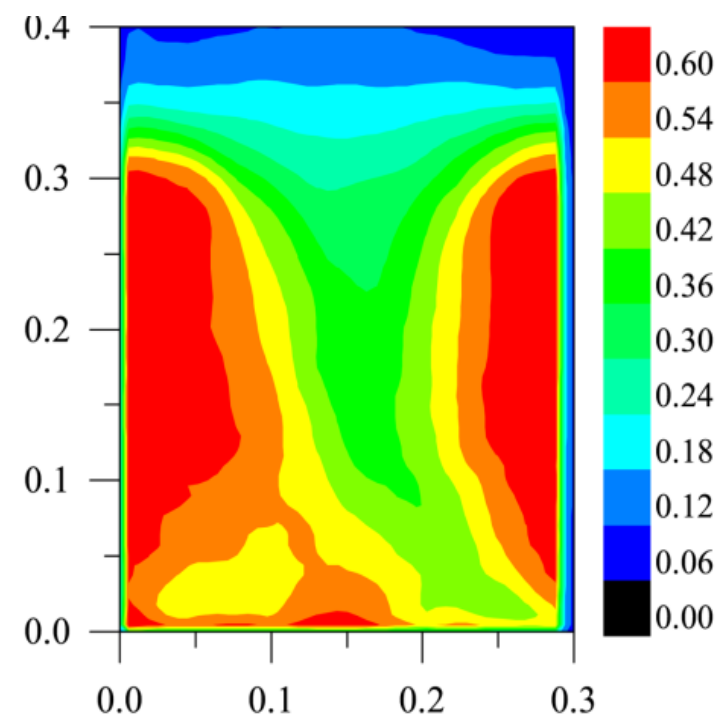

(c)

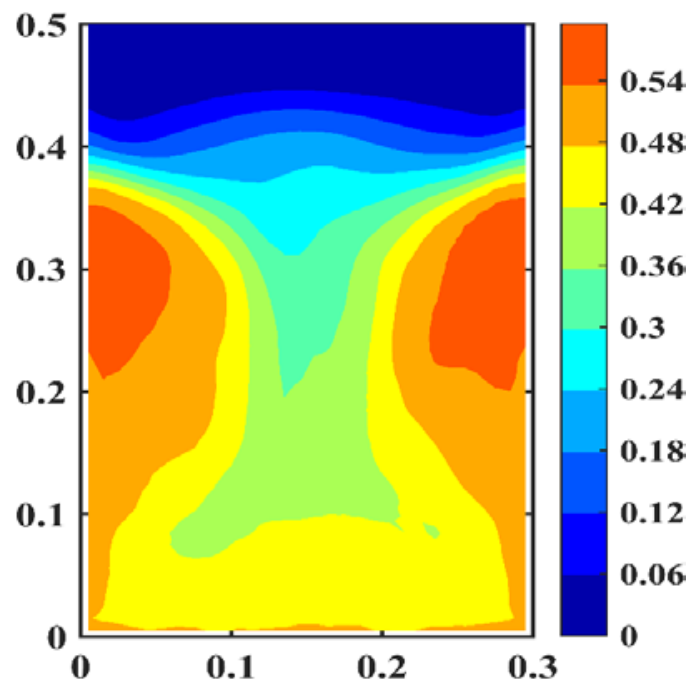

(b)

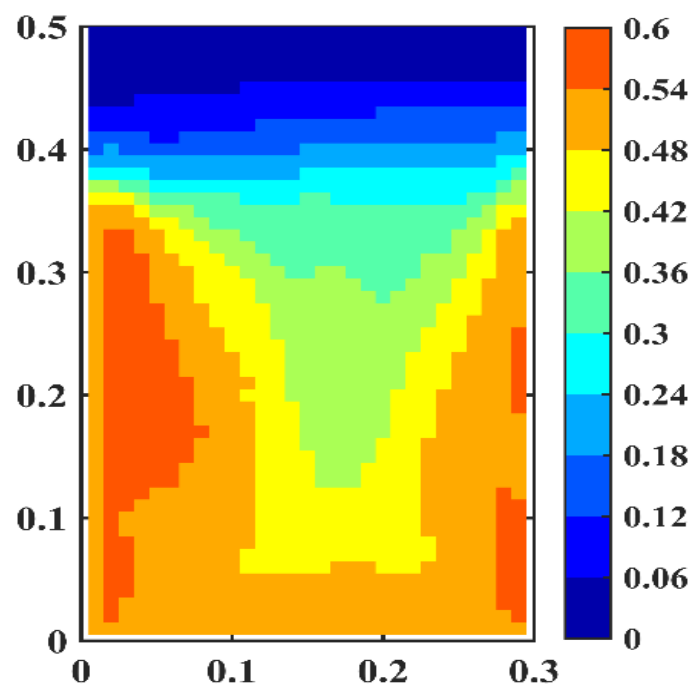

(d)

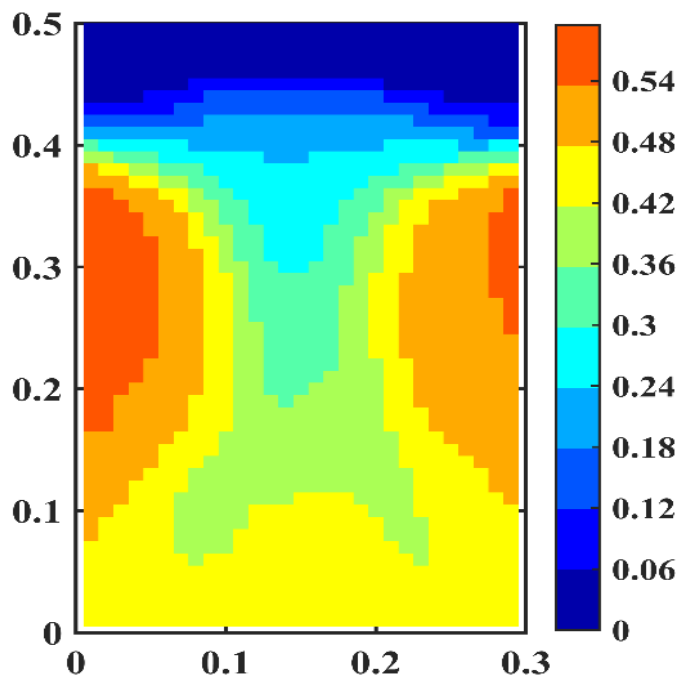

Fig. 5. Comparison of time-averaged solids volume fraction for PIV-DIA (Buist et al., 2014) and simulations (5-25 s), (a), PIV-DIA (Buist et al., 2014); (b), DPM simulation; (c), Model A; (d), Model B, $U_{\mathrm{g}}=2.35 \mathrm{~m} / \mathrm{s}$. 
A comparison of the distribution of translational granular temperature predicted by the three models is shown in Fig. 6 at superficial gas velocity of $2.35 \mathrm{~m} / \mathrm{s}$. A very clear difference between the DPM simulations on the one hand and both TFM simulations on the other hand can be observed at heights above $0.4 \mathrm{~m}$, with the former predicting very low granular temperatures and the latter very high granular temperatures. This is an artifact caused by the fact that the region above $0.4 \mathrm{~m}$ is extremely dilute (see Fig. 5). As a consequence in the DPM simulations often only 0 or 1 particles are present per computational cell, and hence no velocity fluctuations can be determined (which is then erroneously recorded as zero granular temperature). On the other hand, because TFM is working with continuous fields, a granular temperature is simulated even in these very dilute regions. In our comparison between DPM and TFM we should therefore exclude this region above $0.4 \mathrm{~m}$. Having said that, in TFM models A and B the zones with high translational granular temperature are still situated mainly at the top of the bed, away from the side walls. Model A predicts a larger zone of high translational granular temperature than model $\mathrm{B}$, however this is influenced by the fact that particle rotation is not yet included in the boundary conditions for rough side walls in Model A, and therefore less energy is dissipated during particle-wall collisions. From the freely bubbling experiment for Geldart D type particles of Bokkers (2005), high values of translational granular temperature are found in the vicinity of the bubbles. Goldschmidt et al. (2004) pointed out that numerical simulations of pseudo 2D fluidized beds predicted a lower granular temperature in areas where the particle volume fraction was high. Our simulation results confirm this finding. The translational granular temperature in all cases has a similar distribution (below $0.4 \mathrm{~m}$ ) and the overall magnitude of the translational granular temperature matches well.

(a)

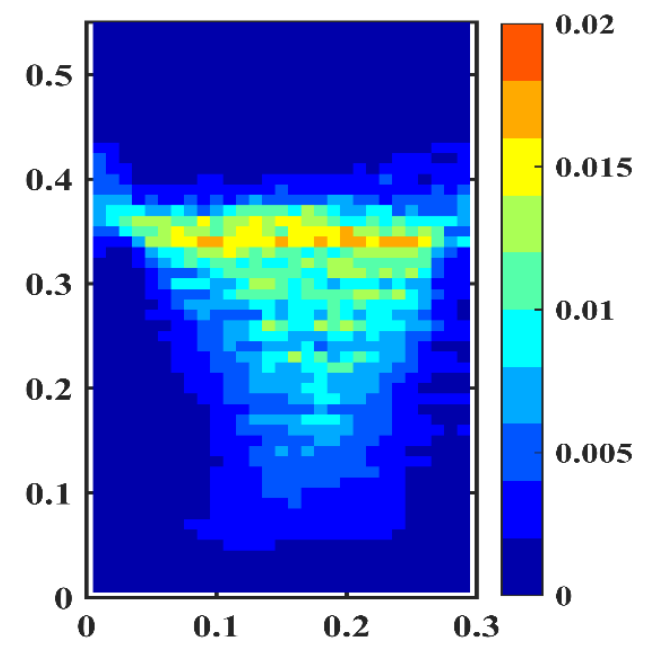

(b)

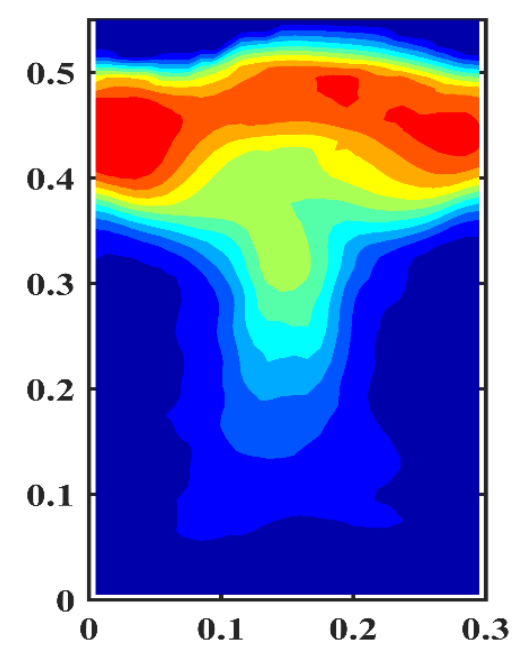

(c)

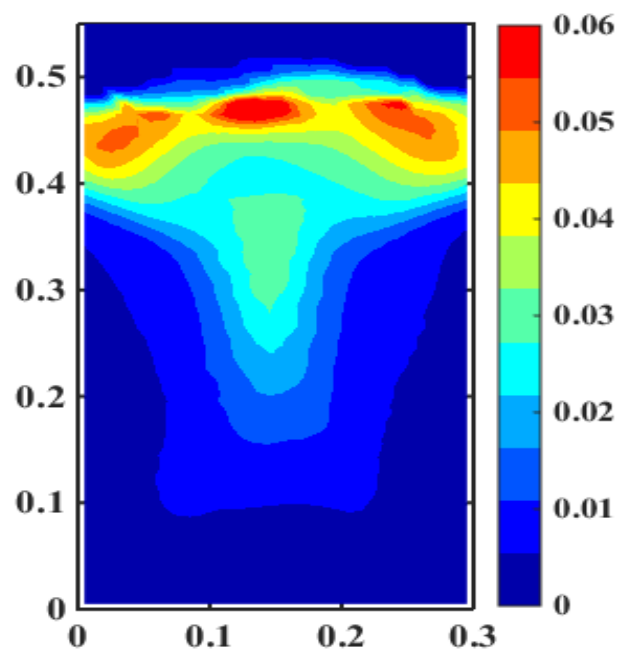

Fig. 6. Contour plots of time-averaged (5-25 s) translational granular temperature $\left(\mathrm{m}^{2} / \mathrm{s}^{2}\right)$ for TFM and DPM at $U_{\mathrm{g}}=2.35 \mathrm{~m} / \mathrm{s}$, (a), DPM simulation; (b), Model A; (c), Model B. 
Fig. 7 shows a quantitative comparison of the translational granular temperature distribution as a function of local solids fraction for the different models. The predicted translational granular temperatures from all the models decrease with increasing of solids fraction. This decrease is mainly due to the increase in the collision frequency between particles, leading to a stronger decrease in relative fluctuating velocities. In the intermediate density regime (solids fraction 0.25-0.4), the simulated granular temperature from model A is higher than that of model B. In the dense regime (solids fraction $>0.45$ ), where the majority of the particles reside, the opposite is true: model A predicts a lower granular temperature than model B. In this dense limit model A is closer to the DPM results than model B, but both KTGF models over-predict the granular temperature. Again we emphasize that further improvements can be expected for model A with better boundary conditions for the particle stress and translational and rotational granular temperature, which are especially important for pseudo-2D systems such as studied here.

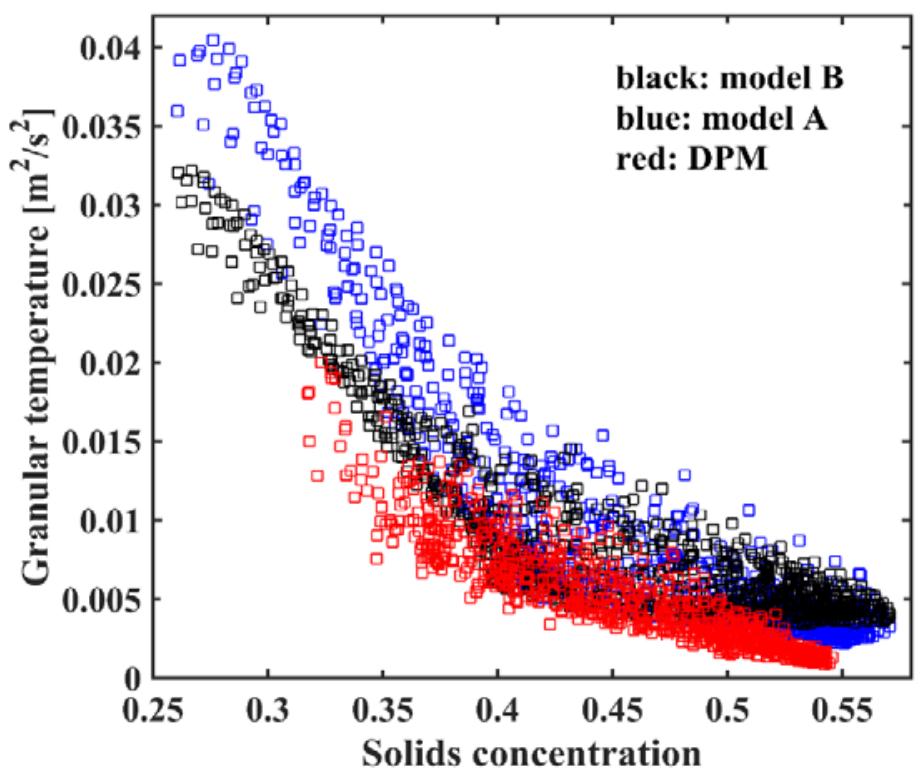

Fig. 7. Time-averaged (5-25 s) translational granular temperature as a function of solids fraction in the bed (sampled at heights between $0.1 \mathrm{~m}$ and $0.35 \mathrm{~m}$ ) fluidized at $U_{g}=2.35 \mathrm{~m} / \mathrm{s}$ for DPM (red), model A (blue), and model B (black). 
Fig. 8 shows contour plots of the rotational granular temperatures of TFM model A and DPM at superficial gas velocity of $2.35 \mathrm{~m} / \mathrm{s}$. The rotational granular temperature in TFM model A shows an almost uniform distribution in the bed, but the overall magnitude agrees to a reasonable extent. In this respect it is important to note that TFM model B has a zero rotational granular temperature, which is further besides the truth. The reason for the uniformity of the rotational granular temperature profile can be found in two major assumptions made in the current version of KTGF. Firstly, the mean rotational velocity is assumed to be zero, which means that in the modelling of particle rotation only the rotational energy balance equation is solved. Secondly, the gradient of the rotational granular temperature at the wall is assumed to be zero (corresponding to adiabatic walls for rotational granular temperature). It is clear that these assumptions may be too coarse, especially near boundaries which may in reality generate an average rotation velocity and generate or absorb rotational fluctuations. We are still working on a careful theory for the boundary conditions for the rotational granular temperature, but we find that preliminary simulations with such improved boundary conditions lead to a much more heterogeneous distribution of the granular temperature throughout the fluidized bed, improving the agreement with DPM simulations. We will show these results in our next paper.

(a)

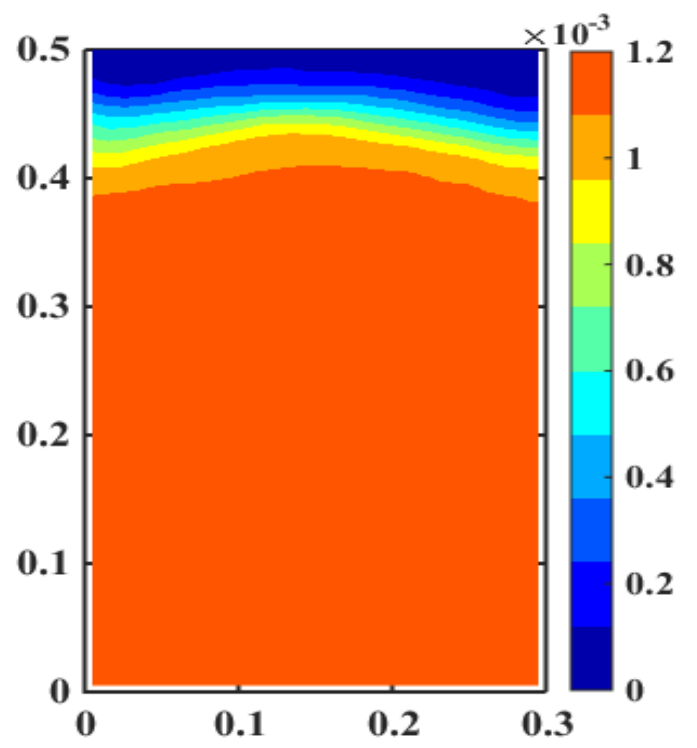

(b)

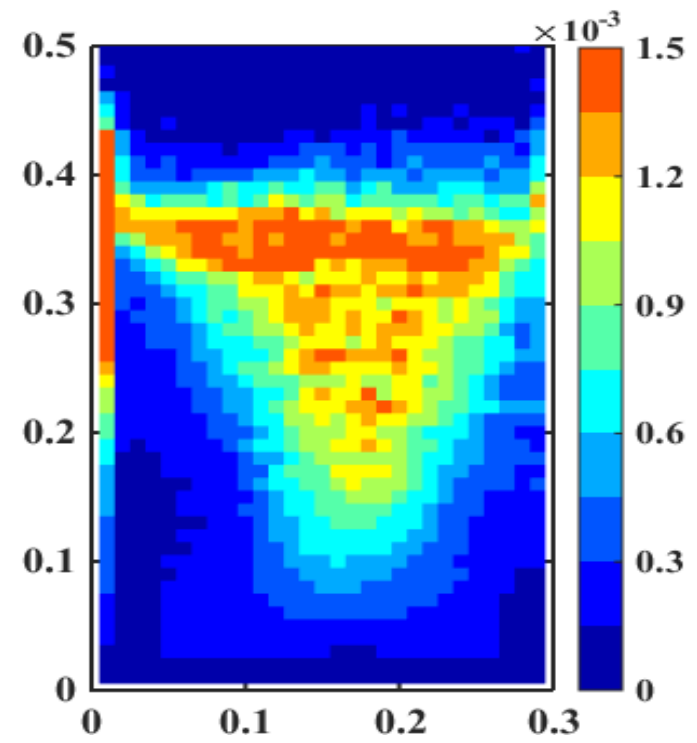

Fig. 8. Contour plots of time-averaged (5-25 s) rotational granular temperature $\left(\mathrm{m}^{2} / \mathrm{s}^{2}\right)$ for TFM and DPM at $U_{g}=2.35 \mathrm{~m} / \mathrm{s}$, (a): model A simulation, (b): DPM simulation. 
Fig. 9 shows the ratio of rotational to translational granular temperature as a function of the solids fraction for DPM and our model A at different superficial gas velocities. In the dilute region (solids volume fraction 0.15-0.35), the predicted temperature ratio from model A is lower than that from DPM simulations. For higher solids volume fractions the temperature ratio simulated by model A is similar to the DPM simulations. According to the kinetic theory of Lun (1991), the ratio of rotational temperature to translational temperature is a function of the tangential coefficient of restitution only and independent of solids concentration. However, in the simulations of Lun and Bent (1994), the measured temperature ratio in simple shear flow of steel spheres with $e=0.93, \beta_{0}=0, \mu=0.123$ shows a relatively pronounced dependence on solids concentration. Moreover, Jenkins and Zhang (2002) presented their analytic expressions of the temperature ratio for steady and unsteady flows. In their theory, the temperature ratio is a function of normal and tangential restitution coefficients, and friction coefficient. This ratio is independent of the solids concentration, and always underestimated compared to the simulation data of Lun and Bent (1994).

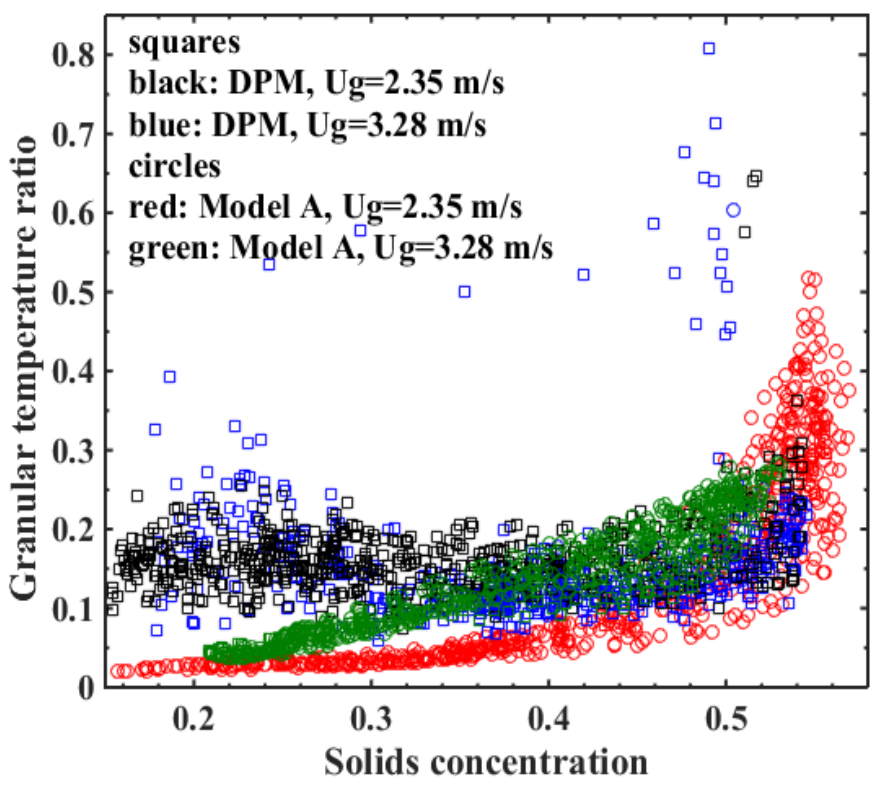

Fig. 9. The time averaged (5-25 s) ratio of rotational to translational granular temperature $\lambda$ predicted by model A (circles $\circ$ ) and DPM (squares $\square$ ) at $U_{g}=2.35 \mathrm{~m} / \mathrm{s}$ and $U_{g}=3.28 \mathrm{~m} / \mathrm{s}$ sampled in the bed at heights between $0.2 \mathrm{~m}$ and $0.4 \mathrm{~m}$.

From Table 5 we find that the distribution of the total energy of the particles across the different contributions are almost the same for TFM model A and DPM (for small inlet gas velocity the deviation between the two models is $1.3 \%$; for large inlet gas velocity the deviation is $0.6 \%$ ). The contributions from the potential energy $\boldsymbol{E}_{\text {pot }}$ and translational granular energy $\boldsymbol{E}_{\text {gran }}$ become larger with increasing superficial gas velocity, which is also found in the simulations of Goldschmidt (2004). For this specific system, it can be concluded that most energy is present as potential energy. However, TFM model B overpredicts the total particle energy due to a too high potential particle energy, which is consistent with the increased average particle height in Fig. 1. At the same time, the amount of convective kinetic energy is underestimated in TFM model B to a large extent. Both the high particle height and low convective kinetic energy in model B are mainly caused by the absence of particle rotation. Therefore, we can conclude that the present model A is superior to model B in the prediction of the particle energy distribution. 
Table 5 Time averaged result of energy balance for particles (10-25 s)

\begin{tabular}{llllllll}
\hline Cases & $\boldsymbol{E}_{\text {tot }}[\mathrm{J}]$ & $\boldsymbol{E}_{\text {kin }}[\mathrm{J}]$ & $\boldsymbol{E}_{\text {pot }}[\mathrm{J}]$ & $\boldsymbol{E}_{\text {conv }}[\mathrm{J}]$ & $\boldsymbol{E}_{\text {gran }}[\mathrm{J}]$ & $\boldsymbol{E}_{\text {rotconv }}[\mathrm{J}]$ & $\boldsymbol{E}_{\text {rotgran }}[\mathrm{J}]$ \\
\hline DPM, $2.35 \mathrm{~m} / \mathrm{s}$ & 4.09 & $0.137(3.32 \%)$ & $3.95(96.7 \%)$ & $0.128(3.1 \%)$ & $0.0093(0.22 \%)$ & $0.0008(0.02 \%)$ & $0.0016(0.04 \%)$ \\
DPM, $3.28 \mathrm{~m} / \mathrm{s}$ & 5.34 & $0.424(7.94 \%)$ & $4.92(92 \%)$ & $0.395(7.4 \%)$ & $0.0236(0.44 \%)$ & $0.0016(0.03 \%)$ & $0.004(0.07 \%)$ \\
& & & & & & & $0.0033(0.08 \%)$ \\
Model A, $2.35 \mathrm{~m} / \mathrm{s}$ & 4.03 & $0.130(3.24 \%)$ & $4.08(98.5 \%)$ & $0.109(2.7 \%)$ & $0.0218(0.54 \%)$ & - & - \\
Model B, $2.35 \mathrm{~m} / \mathrm{s}$ & 4.26 & $0.093(2.0 \%)$ & $4.17(98 \%)$ & $0.070(1.4 \%)$ & $0.0226(0.6 \%)$ & - & \\
& & & & & & & $0.0073(0.13 \%)$ \\
Model A, 3.28 m/s & 5.31 & $0.303(5.7 \%)$ & $5.00(94.2 \%)$ & $0.251(4.7 \%)$ & $0.052(1 \%)$ & - & - \\
Model B, 3.28 m/s & 5.42 & $0.212(3.9 \%)$ & $5.21(96.1 \%)$ & $0.159(2.9 \%)$ & $0.053(1 \%)$ & - & \\
\hline
\end{tabular}

Fig. 10 shows the distribution of the total energy dissipation, as measured in model A and model B, as a function of the solids concentration. The simulated total energy dissipation from both models increases with increasing solids concentration from $0-0.3$, decreases when the solids concentration is in the range of 0.3-0.4, and finally reaches a plateau. The predicted total energy dissipation from model A is larger than that from model B. From the expressions for the translational and rotational energy dissipation (Eqs. (T10) and (T11)), it can be seen that both expressions have two terms. The first term relates to the collisional rate of kinetic energy interchange. It incorporates the energy dissipation from inelasticity and particle surface friction. The second term includes the velocity divergence. This term represents energy losses due to compression of granular material. The total energy dissipation is the combination of these two terms. Model A considers not only the particle surface friction but also particle rotation. As a result, model A predicts a larger amount of energy dissipation.

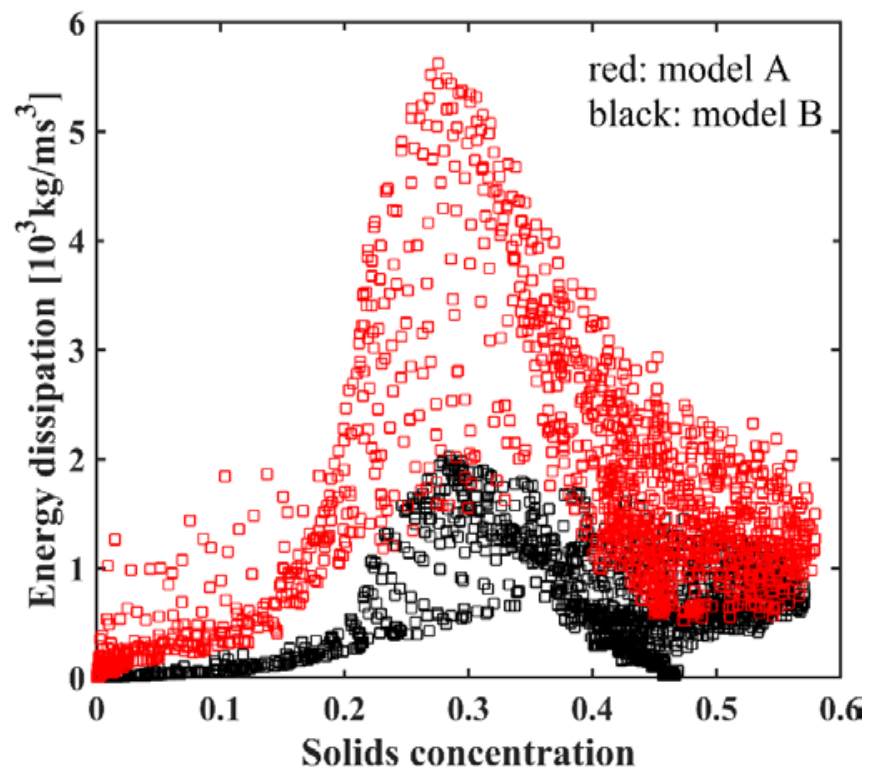

Fig. 10. Time-averaged (5-25 s) energy dissipation over solids concentration with different models at $U_{g}=2.35 \mathrm{~m} / \mathrm{s}$ in the bed. 
Finally, Fig. 11 shows instantaneous snapshot of bubble patterns at different times obtained by different models. These figures show that small bubbles are generated at the bottom, then bubbles grow in size due to coalescence, and move towards the center due to a lower resistance at the center (Kunii \& Levenspiel, 1991). Comparing TFM models A and B, it can be observed that both larger bubbles and larger densely packed regions are formed in TFM model A as a result of the increased energy dissipation associated with particle rotation. Although the particles distribute more homogeneously in the DPM simulations, slugging fluidization is observed in both the DPM simulation and in the TFM model A simulation, while the phenomena in TFM model B are not clear. In conclusion, TFM model A agrees better with the DPM simulations than TFM model B, showing the importance of modelling the particle rotations.

\section{0s}
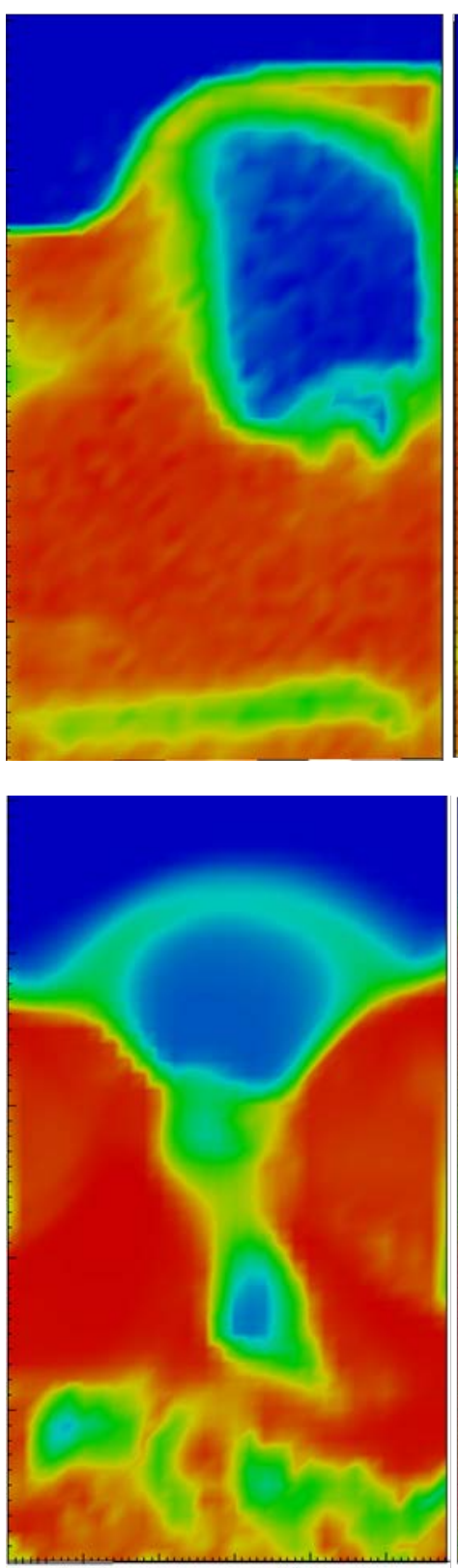

$7.4 \mathrm{~s}$
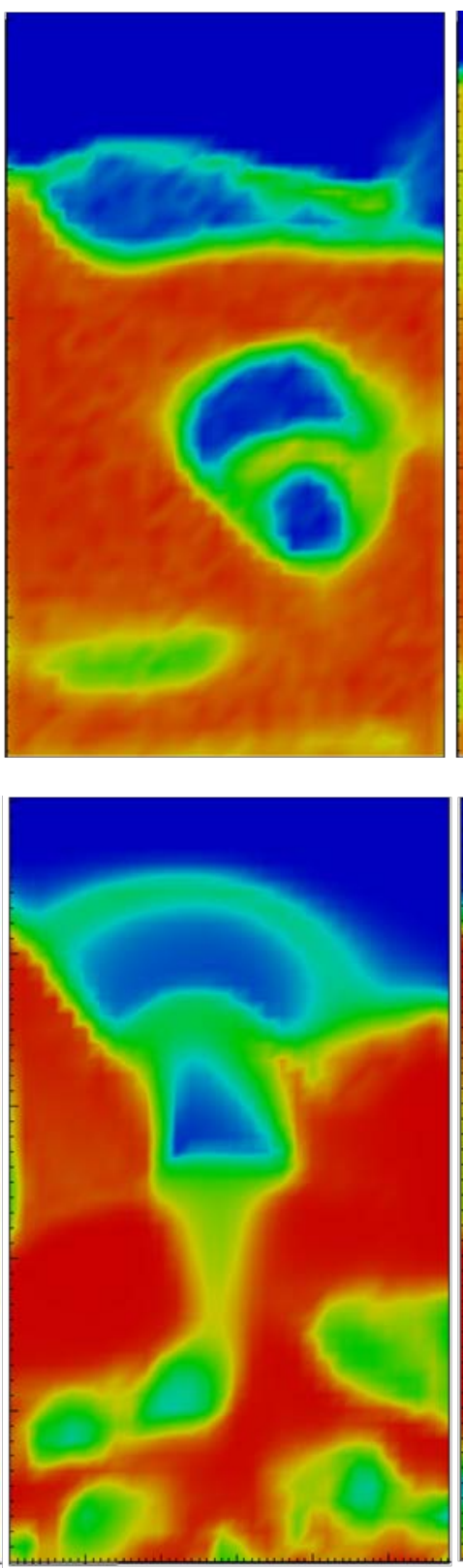

8.8s
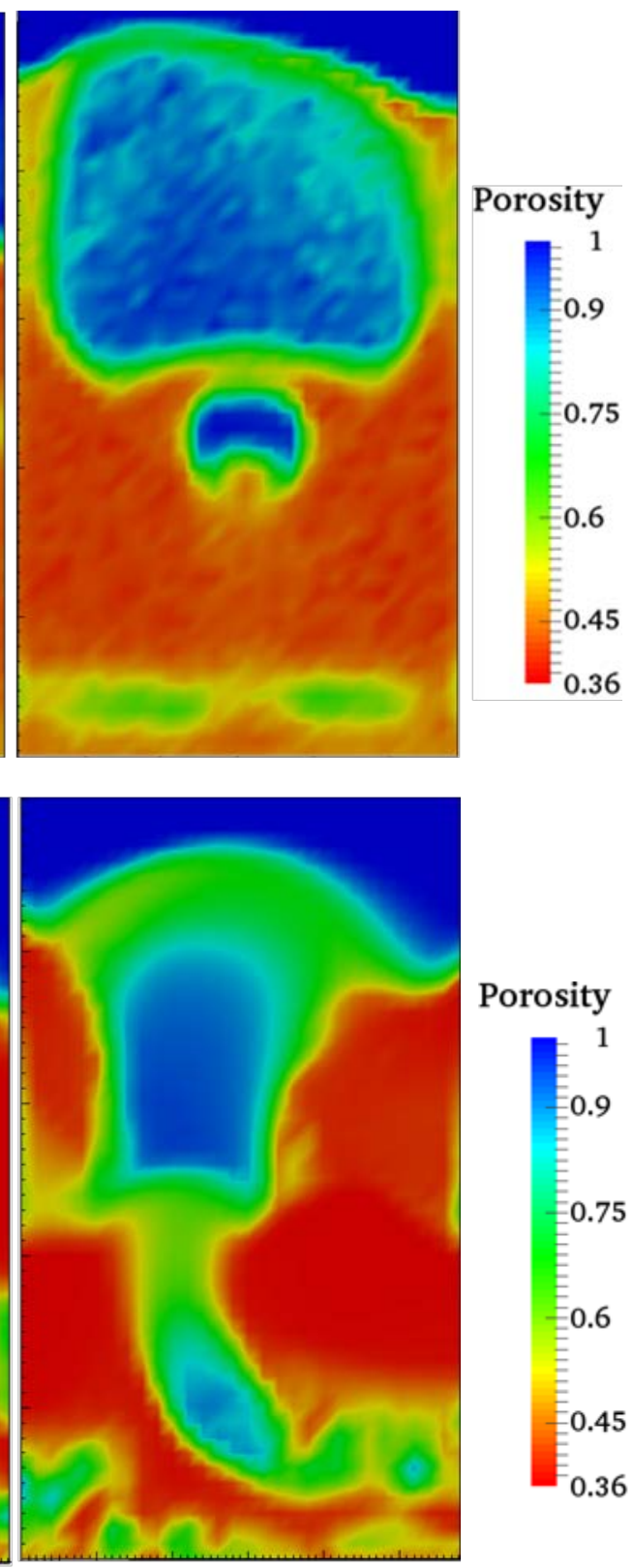

\section{Porosity}

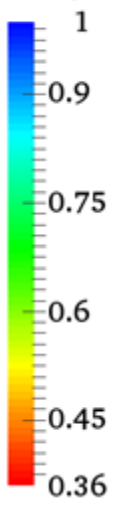



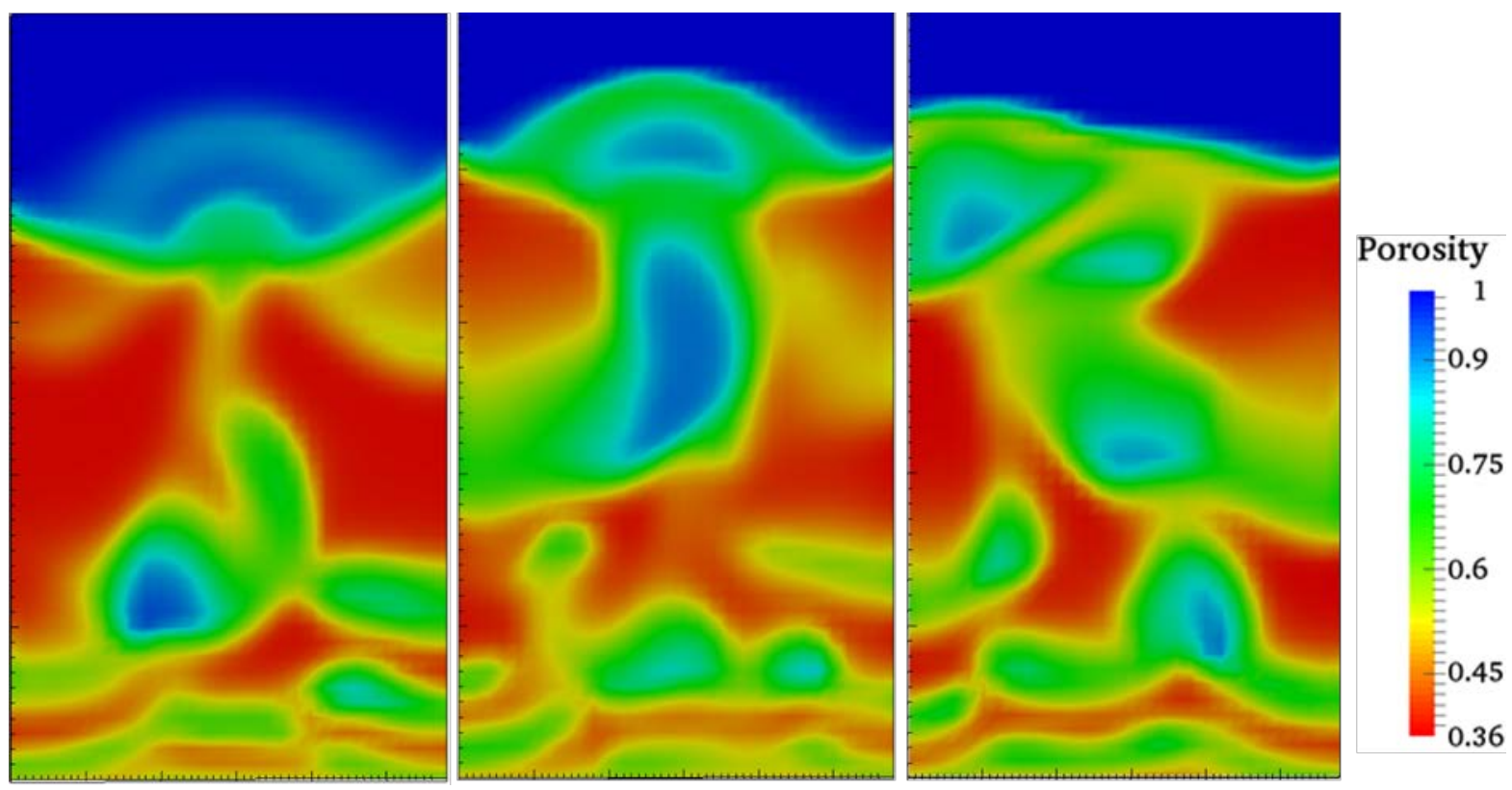

Fig. 11. Instantaneous snapshot of gas fraction from different simulations at $U_{\mathrm{g}}=2.35 \mathrm{~m} / \mathrm{s}$, top: DPM simulation, middle: TFM model A simulation, bottom: TFM model B simulation.

\section{Conclusions}

The hydrodynamics of a dense solid-gas fluidized bed has been studied using kinetic theory of granular flow (KTGF) for rough spheres. The two-fluid model (TFM) simulations are validated by comparing with PIV-DIA experiments and DPM simulations of the same dense solid-gas fluidized bed. We find that the TFM model with particle rotations (model A) agrees well with PIV-DIA experimental results of averaged particle axial velocity and solids volume fraction. Moreover, the predicted distribution of the translational granular temperature in TFM model A agrees closely with the results from DPM. Also the solids circulation pattern compares reasonably well with the results found in the DPM simulation. However, the predicted rotational granular temperature in the present model A shows an almost uniform distribution in the bed as a result of the assumptions of zero mean rotational velocity and adiabatic boundary conditions for the rotational granular temperature. Thus, although the present model A can probably already be used for the study of bulk conditions in dense solid-gas fluidized beds, proper boundary conditions should be derived and implemented for the rotational granular temperature and the rotational velocity, and the assumption of zero mean rotational velocity should be relaxed. This will be the next topic of our research.

We have performed comparisons between the validated present model A and the results of a simpler kinetic theory for rapid flow of slightly frictional, nearly elastic spheres derived by Jenkins and Zhang (2002) (model B). The simulation results show that model A produces better agreement with DPM simulation results in terms of time-averaged axial particle velocity, solids volume fraction and the particle energy distribution compared to model B. It can be concluded that the present model improves the predictions obtained from the model derived by Jenkins and Zhang (2002).

\section{Nomenclature}

I moment of inertial

$m \quad$ mass of the particle, $\mathrm{kg}$

n $\quad$ particle number density

$U_{m f} \quad$ minimum fluidization velocity, $\mathrm{m} / \mathrm{s}$ 


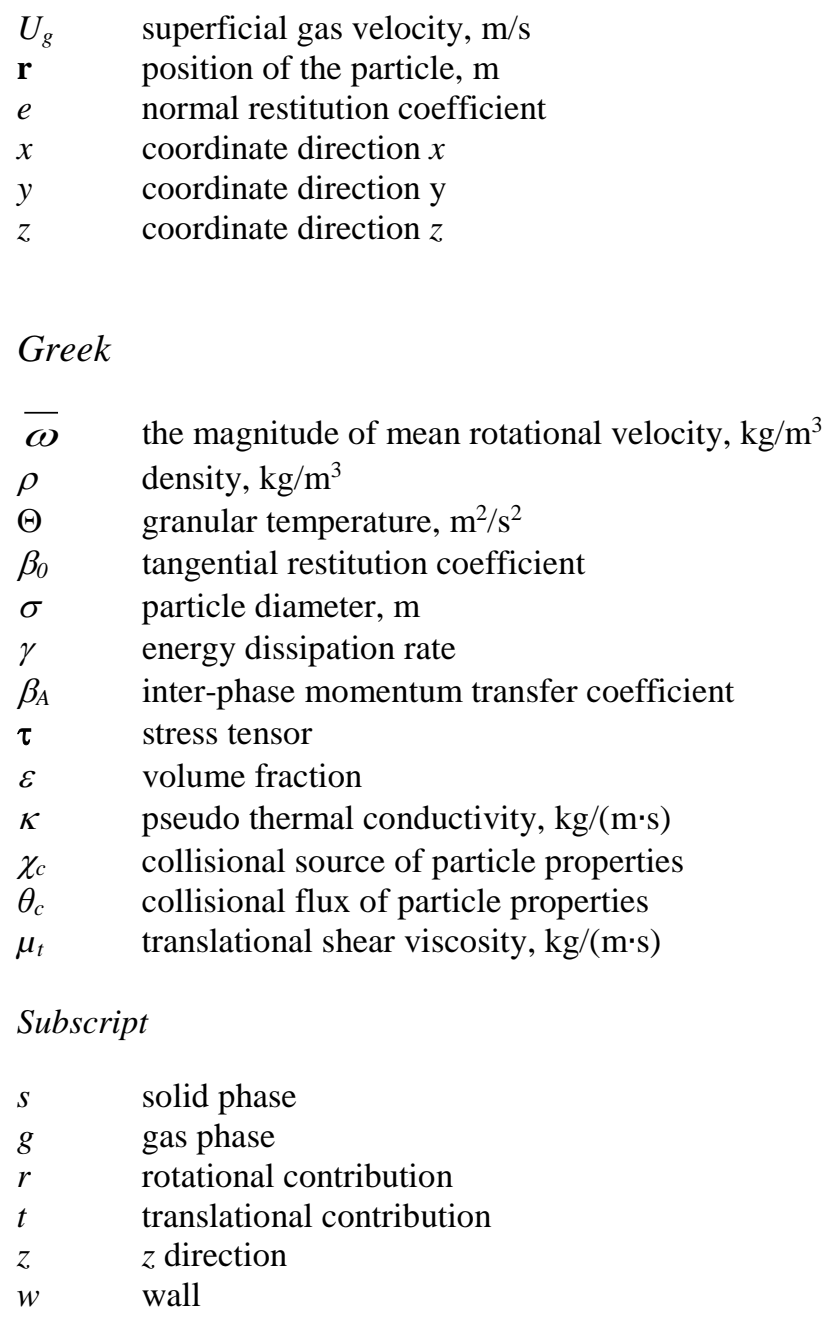

\section{Acknowledgment}

The authors would like to thank the European Research Council for its financial support, under its Advanced Investigator Grant scheme, Contract no. 247298 (Multi-scale Flows).

\section{References}

Bokkers, G. A., 2005. Multi-level modelling of the hydrodynamics in gas phase polymerization reactors. Ph.D. Thesis, Twente University, Enschede, The Netherlands.

Beetstra, R., Van der Hoef, M. A., Kuipers, J. A. M., 2007. Drag force of intermediate Reynolds number flow past mono-and bidisperse arrays of spheres. AIChE Journal 53, 489-501.

Buist, K. A., Deen, N. G., Kuipers, J. A. M., 2014. Improved magnetic particle tracking technique in dense gas fluidized beds. AIChE Journal 60, 3133-3142.

Chialvo, S., Sundaresan, S., 2013. A modified kinetic theory for frictional granular flows in dense and dilute regimes. Physics of Fluids 25, 070603.

Ding, J. M., Gidaspow, D., 1990. A bubbling fluidization model using kinetic theory of granular flow. AIChE Journal 36, 523-538.

Deen, N. G., Annaland, M. V. S., Van der Hoef, M. A., Kuipers, J. A. M., 2007. Review of discrete particle modeling of fluidized beds. Chemical Engineering Science 62, 28-44. 
de Jong, J. F., Odu, S. O., van Buijtenen, M. S., Deen, N. G., van Sint Annaland, M., Kuipers, J. A. M., 2012. Development and validation of a novel digital image analysis method for fluidized bed particle image velocimetry. Powder Technology 190, 193-202.

Enwald, H., Peirano, E., Almstedt, A. E., 1996. Eulerian two-phase flow theory applied to fluidization. International Journal of Multiphase Flow 22 (Sup.), 21-66.

Ergun, S., 1952. Fluid flow through packed columns. Chemical Engineering Proceedings 48, 89.

Goldshtein, A., Shapiro, M., 1995. Mechanics of collisional motion of granular materials. Part1. General hydrodynamic equations. Journal of Fluid Mechanics 282, 75-114.

Gidaspow, D., 1994. Multiphase flow and fluidization: continuum and kinetic theory descriptions. Academic Press, New York, USA.

Goldschmidt, M. J. V., Beetstra, R., Kuipers, J. A. M., 2004. Hydrodynamic modelling of dense gasfluidised beds: comparison and validation of 3D discrete particle and continuum models. Powder Technology 142, 23-47.

Hoomans, B. P. B., Kuipers, J. A. M., Briels, W. J., Van Swaaij, W. P. M., 1996. Discrete particle simulation of bubble and slug formation in a two-dimensional gas-fluidised bed: a hard-sphere approach. Chemical Engineering Science 51, 99-118.

Jenkins, J. T., Savage, S. B., 1983. A theory for the rapid flow of identical, smooth, nearly elastic, spherical particles. Journal of Fluid Mechanics 30, 187-202.

Jenkins, J. T., Zhang, C., 2002. Kinetic theory for identical, frictional, nearly elastic spheres. Physics of Fluids 14, 1228-1235.

Kunii, D., Levenspiel, O., 1991. Fluidization Engineering, 2nd edition, Butterworth-Heinemann, Boston.

Kuipers, J. A. M., van Duin, K. J., van Beckum, F. P. H., van Swaaij, W. P. M., 1992. A numerical model of gas-fluidized beds. Chemical Engineering Science 47, 1913.

Kuipers, J. A. M., Van Duin, K. J., Van Beckun, F. P. H., van Swaaij, W. P. M., 1993. Computer simulation of the hydrodynamics of a two-dimensional gas-fluidised bed. Computers \& Chemical Engineering 8, 839-858.

Kuipers, J. A. M., Van Swaaij, W. P. M., 1998. Computational fluid dynamics applied to chemical reaction engineering. Advances in chemical engineering 24, 227-328.

Kumaran, V., 2006. The constitutive relation for the granular flow of rough particles, and its application to the flow down an inclined plane. Journal of Fluid Mechanics 561, 1-42.

Li, J. H., Ouyang, J., Gao, S. Q., Ge, W., Yang, N., Song, W., 2005. Multi-Scale Simulation of ParticleFluid Complex Systems. Science Press, Beijing, China.

Lun, C. K. K., 1991. Kinetic theory for granular flow of dense, slightly inelastic, slightly rough spheres. Journal of Application Mechanics 233, 539-559.

Lun, C. K. K., Bent, A. A., 1994. Numerical simulation of inelastic frictional spheres in simple shear flow. Journal of Fluid Mechanics 258, 335-353.

Lu, H. L., He, Y. R., Liu, W. T., Ding, J. M., Gidaspow, D., Bouillard, J., 2004. Computer simulations of gas-solid flow in spouted beds using kinetic-frictional stress model of granular flow. Chemical Engineering Science 59, 865-878.

Laverman, J. A., Fan, X., Ingram, A., van Sint Annaland, M., Parker, D. J., Seville, J. P. K., Kuipers, J. A. M., 2012. Experimental study on the influence of bed material on the scaling of solids circulation patterns in 3D bubbling gas-solid fluidized beds of glass and polyethylene using positron emission particle tracking. Powder Technology, 224, 297-305.

Ma, D., Ahmadi, G., 1986. An equation of state for dense rigid sphere gases. The Journal of Chemical Physics 84, 3449-3450.

Nieuwland, J. J., 1995. Hydrodynamic Modelling of Gas-Solid Two-Phase Flows (Ph.D. thesis). Twente University, Enschede, the Netherlands.

Ozel, A., Fede, P., Simonin, O., 2013. Development of filtered Euler-Euler two-phase model for circulating fluidised bed: high resolution simulation, formulation and a priori analyses. International Journal of Multiphase Flow 55, 43-63. 
Ristow, G. H., 2000. Pattern formation in granular materials. No. 164. Springer Science \& Business Media.

Sinclair, J., Jackson, R., 1989. Gas-Particle Flow in a Vertical Pipe with Particle-Particle Interactions. AIChE Journal 35, 1473.

Sun, D., Wang, S. Y., Lu, H. L., Shen, Z. H., Li, X., Wang, S., Zhao, Y. H., Wei, L. X., 2009. A secondorder moment method of dense gas-solid flow for bubbling fluidization. Chemical Engineering Science 64, 5013-5027.

Tsuji, Y., Kawaguchi, T., Tanaka, T., 1993. Discrete particle simulation of two-dimensional fluidized bed. Powder technology 77, 79-87.

Van der Hoef, M. A., Ye, M., van Sint Annaland, M., Andrews, A. T., Sundaresan, S., Kuipers, J. A. M., 2006. Multiscale modeling of gas-fluidized beds. Advances in Chemical Engineering 31, 65-149.

Van der Hoef, M. A., Beetstra, R., Kuipers, J. A. M., 2005. Lattice-Boltzmann simulations of lowReynolds number flow past mono- and bidisperse arrays of spheres: results for the permeability and drag force. Journal of Fluid Mechanics 528, 233-254.

Van Buijtenen, M. S., Van Dijk, W. J., Deen, N. G., Kuipers, J. A. M., Leadbeater, T., Parker, D. J., 2011. Numerical and experimental study on multiple-spout fluidized beds. Chemical engineering science 66, 2368-2376.

van Buijtenen, M. S., Börner, M., Deen, N. G., Heinrich, S., Antonyuk, S., Kuipers, J. A. M., 2011. An experimental study of the effect of collision properties on spout fluidized bed dynamics. Powder Technology 206, 139-148.

Verma, V., Padding, J. T., Deen, N. G., 2015. Effect of bed size on hydrodynamics in 3-D gas-solid fluidized beds. AIChE Journal 61, 1492-1506.

Wang, S., Hao, Z. H., Lu, H. L., Liu, G. D., Wang, J. X., Xu, P. F., 2012. A bubbling fluidization model using kinetic theory of rough spheres. AIChE Journal 58, 440-455.

Walton, O. R., 1992. Numerical simulation of inelastic, frictional particle-particle interactions, in Particulate Two-Phase Flow, Part I, edited by M.C. Roco, Butterworth-Heinemann, Boston, 884.

Wen, C. Y., Yu, Y. H., 1966. Mechanics of fluidization. AIChE Series 62, 100.

Zhu, H. P., Zhou, Z. Y., Yang, R. Y., Yu, A. B., 2007. Discrete particle simulation of particulate systems: theoretical developments. Chemical Engineering Science 62, 3378-3396.

Zhao, Y., Lu, B., Zhong, Y., 2013. Euler-Euler modeling of a gas-solid bubbling fluidized bed with kinetic theory of rough particles. Chemical Engineering Science 104, 767-779. 